\title{
INTERFACE ADHESION: EFFECTS OF PLASTICITY AND SEGREGATION
}

\author{
A. G. EVANS, J. W. HUTCHINSON $\dagger$ and Y. WEI \\ Division of Engineering and Applied Sciences, Harvard University, Cambridge, MA 02138, U.S.A.
}

\begin{abstract}
The adhesion at interfaces between dissimilar materials is strongly affected by both segregation and the extent of plasticity in the adjoining material, particularly when one of these is a metal (or thermoplastic). It will be shown that these interfaces when clean, are generally strong and tough, such that failure occurs in one of the adjoining materials, rather than at the interface. However, segregrants and contaminants often embrittle and weaken the interface, especially in combination with ambient moisture. The embrittlement is obviated either by alloying with elements that "getter" the contaminants or by using an "adhesion layer" that has essentially the same effect: $\mathrm{Cr}$ and $\mathrm{Ti}$ are particularly effective gettering elements. Models that relate these effects to fundamental material parameters through non-dimensional indices are described. They comprise linkages between atomistic and continuum, enabled by implementation of a plasticity length scale, within the context of a crack growth simulation routine. Comparison with the experimental results is conducted, leading to suggestions for development of a predictive scheme. (C) 1999 Acta Metallurgica Inc. Published by Elsevier Science Ltd. All rights reserved.
\end{abstract}

Keywords: Multilayers; Thin films; Ceramics; Metals; Fracture and fracture toughness

\section{INTRODUCTION}

The physics and mechanics of bimaterial interface adhesion have now been developed to a level comparable to that for cohesion in homogeneous, isotropic solids [1-10]. Commonalties in behavior have been identified that enable established results for the latter [11-16] to be applied to interfaces. The familiar phenomena include transitions from brittleto-ductile crack growth, crack blunting $[15,16]$ and resistance curves [12, 17] (Figs 1 and 2). However, there are crucial differences.

(i) There are major effects on adhesion of small concentrations of impurities and segregants [9, 18-20].

(ii) A relative paucity of systematic experimental results for interfaces have impeded validation of the ideas and the models.

There are both experimental and theoretical challenges. The former comprises the difficulty in systematically changing just one of the variables: typically, several change simultaneously. The theoretical challenge concerns development of an approach for linking atomistics to continuum. Recent developments in both areas have provided a new opportunity for progress, elaborated in this article.

The progress comprises new adhesion models, particularly for interfaces between metals and oxides. These involve a convolution of the stress and energy levels needed to rupture interface bonds with

$\dagger$ To whom all correspondence should be addressed. the energy dissipated by inelastic flow in the ductile constituents. While the models are closely similar to those used for monolithic metals, at interfaces there is a pre-eminent requirement for a plasticity length scale [21-23].

This article is organized in the following manner. (i) The approaches used for measuring interface mechanical properties are discussed. (ii) A brief overview is given of the mechanisms of interface fracture, along with the basic mechanics, as needed to establish perspectives for the remainder of the article. (iii) Based on the mechanisms, the parameters that characterize adhesion are summarized, including the length scales involved. (iv) A separate section is devoted to the plasticity length scale. (v) The available interface rupture models are compared and contrasted. (vi) A detailed synopsis is given of those measurements and observations made on metal/oxide interfaces relevant to quantitative interpretation. (vii) A comparison of these measurements with the models is presented.

\section{MEASUREMENT STRATEGIES}

Two types of measurement are relevant to adhesion: (i) the stress at which the interface separates [24], and (ii) the energy dissipated per unit area upon extending a crack along the interface [25] (in $\mathrm{J} / \mathrm{m}^{2}$ ). The latter has the same role as the fracture toughness in homogeneous materials [11-17] and accordingly, is the most fundamental, deterministic measure of adhesion. The former includes effects of defects and of stress concentrations (especially at free edges [26]) and is thus test-specific and 


\section{INTERFACE CRACK
GROWTH MECHANISMS}
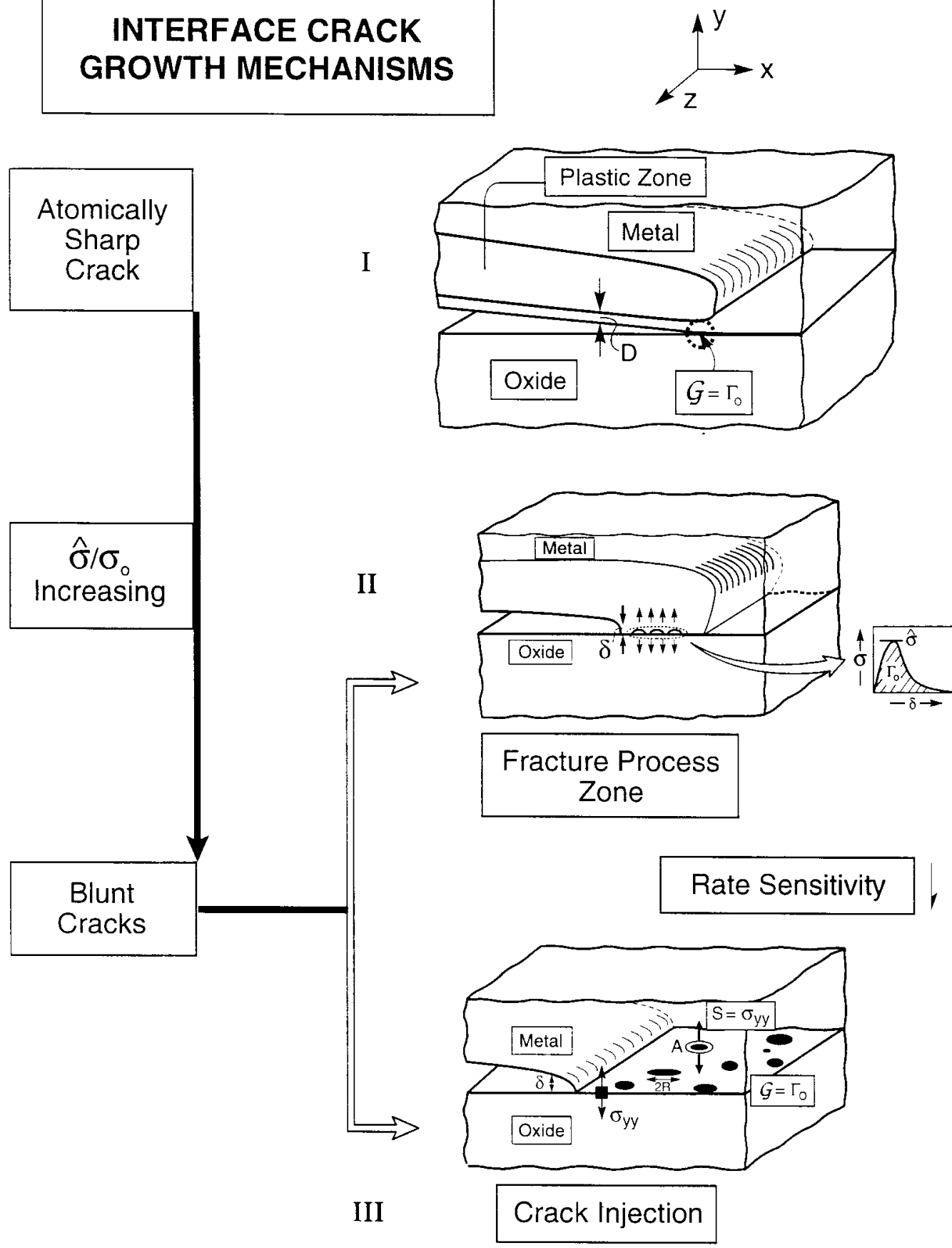

Fig. 1. A schematic of three basic mechanisms that control interface crack growth. In mechanism I, the crack remains atomically sharp. Mechanisms II and III occur subsequent to crack blunting. Mechanism II involves a rupture process zone on the interface that comprises debonds and voids that form and coalesce to extend the crack. Mechanisms I and II exhibit resistance-curve behavior with the steady-state toughness trends illustrated on Fig. 2. Mechanism III involves the injection of cracks onto the interface from weak patches ahead of a stationary crack. There is no resistance curve.

inherently stochastic. Both are important. Here, the energy density measure is emphasized since it is amenable to quantitative comparison with models. This strategy is completely analogous with that used so successfully to characterize the mechanical behavior of homogeneous metals $[11,16]$.
Conducting such studies on interfaces is often more challenging than the corresponding studies performed on their homogeneous counterparts. There are two main issues. (i) The geometric configurations encompassing interfaces of practical interest often constrain specimen design [9, 27-29]. 


\section{Toughening Levels}

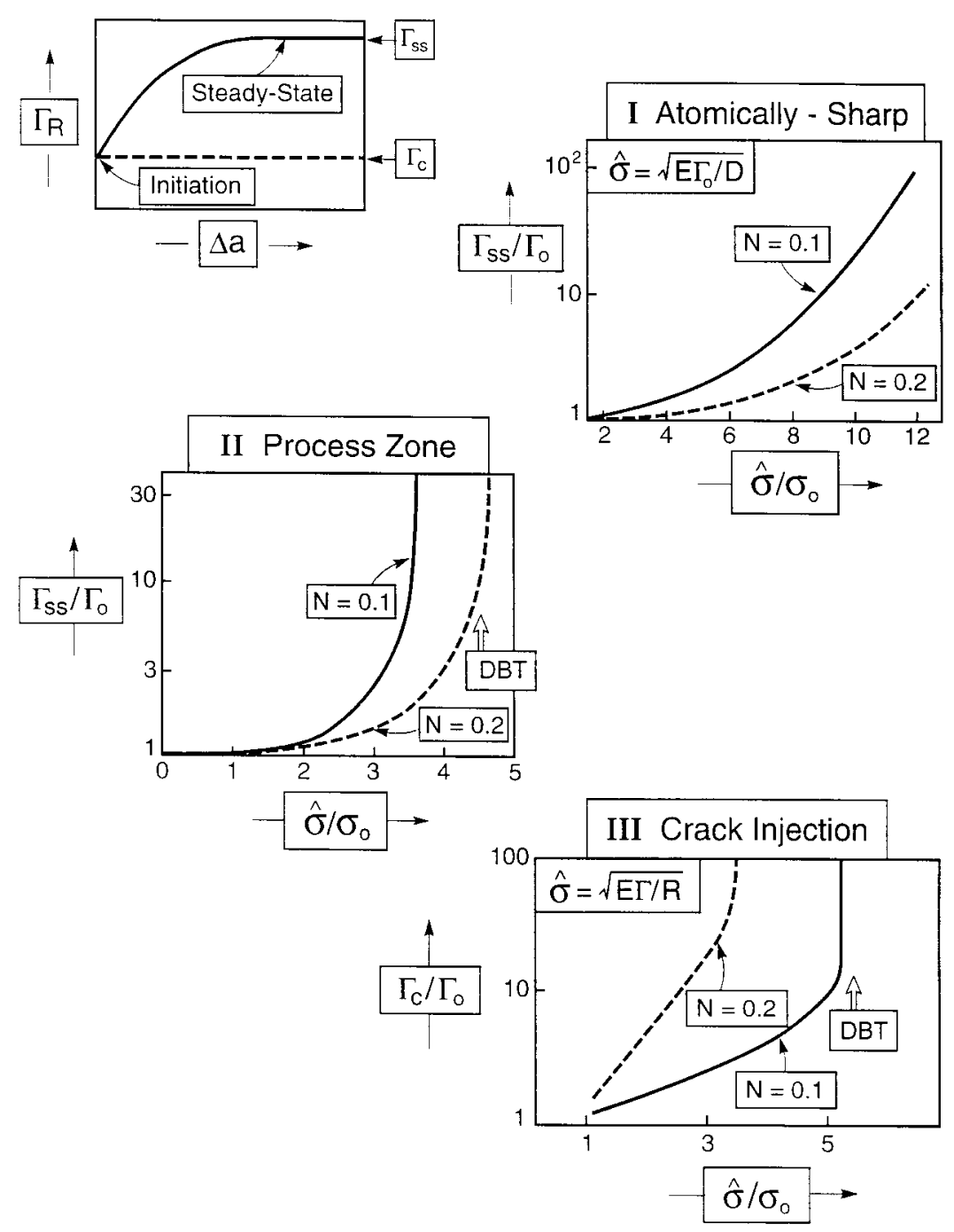

Fig. 2. The three mechanisms shown on Fig. 1 have characteristic toughness features. These are compared and contrasted by using common adhesion indices. Note that the adhesion index, $\Gamma_{\mathrm{Ss}} \Gamma_{\mathrm{o}}$, refers to steady state for mechanisms I and II, but to initiation for mechanism III $\left(\Gamma_{\mathrm{c}} \Gamma_{\mathrm{o}}\right)$. The strength index is defined in each case on the insets. The role of the plasticity length scale has not been included. Its effect is addressed in subsequent figures. The notation DBT refers to a transition condition to rupture of one of the adjoining materials rather than the interface. At strength indices above this transition, the interface mechanism no longer operates, because it cannot be activated by the stresses that arise in the plastic zone. Note that the scales are different, especially on the abscissa.

(ii) Large-scale inelastic deformations limit options $[4,5,9]$, because of the vastly different thermomechanical properties of the adjoining materials.

When interfaces can be made by bonding procedures (such as diffusion bonding or brazing), many different configurations are available for testing, based on those developed for homogeneous systems $[25,30,31]$. The main restriction is that residual stresses often exist and these must be taken into account in determining the energy release rate, $G$, and mode mixity angle $\psi[25,32,33]$. Among these configurations, those that exhibit stable crack growth are preferred, wherein $G$ decreases with an increase in interface crack length, $a$, at specified load, $P$, or displacement $[30,31]$. Such configurations greatly facilitate the introduction of welldefined pre-cracks before conducting the adhesion measurement. For mode I, the double cleavage drilled compression (DCDC) specimen has this feature and has been used successfully to test metal/ oxide and polymer/inorganic interfaces [30, 31, 34] [Fig. 3(a)]. For mixed-mode loading, bending 
a) Double Cleavage Drilled Compression

$$
\psi \approx 0^{\circ}
$$

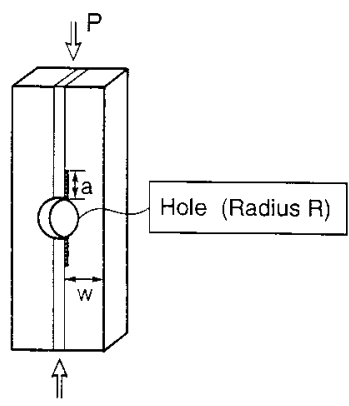

b) Mixed Mode Flexure

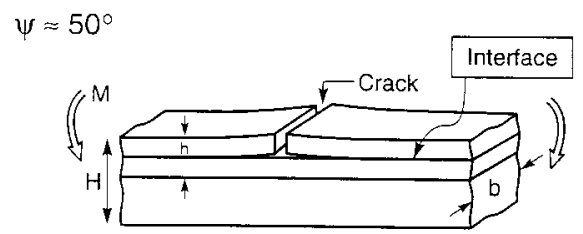

Fig. 3. Test configurations used to measure the interface toughness on bonded bimaterial systems: (a) mode I DCDC configuration; (b) mixed-mode flexure specimen.

configurations are applicable [32, 35] [Fig. 3(b)]. In both cases, when one of the constituents is transparent, optical imaging may be used to monitor the mechanism of crack growth [35, 36].

When one of the constituents is a thin film or coating, few quantitative methods exist for measuring adhesion. There are two basic approaches.

(i) Loads are applied to the film and the displacements measured upon decohesion of the interface. Such methods are exemplified by the peel test [37-39]. This test (and others like it) has the advantage of testing simplicity, at least for ductile or compliant films, but the interpretation is complex. The problem is that the work done is not solely governed by the energy expended around the crack (Fig. 4). As the crack extends, it experiences a bending moment $M$ near its tip. This causes yielding near the crack, but also on the top of the film. Such deformations cause the film to curl, with curvature, $\kappa$ [Fig. 4(I)]. However, because decohesion is induced by a force applied at a specific inclination to the surface, the film must be bent back into this orientation [Fig. 4(II)]. This is realized through an opposite bending moment, $M_{\infty}$, resulting in reverse yielding. The yield zones $O$ (near-tip bending), $A$ and $B$ (reverse bending) comprise redundant plastic work which convolutes with the interfacial work of rupture. Deconvoluting the measurements in a manner that isolates the adhesion is challenging $[38,39]$.

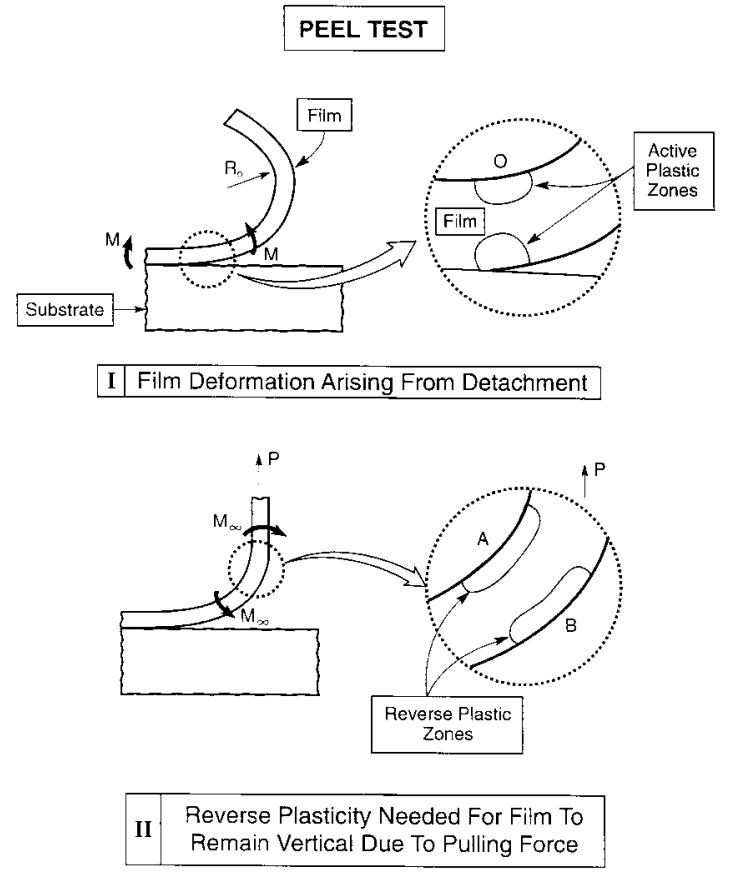

Fig. 4. The peel test with a schematic indicating the plastic zones that arise because of bending (near-tip and reverse), which complicate interpretation of the measurements. In I, film curvature that arises because of the moment $M$ near the tip that causes decohesion, with consequent plasticity. In II, the straightening of the film required by the applied loading is demonstrated, along with the zones of reverse yielding.

(ii) Residual strains are introduced by various means and the extent of the interface decohesion caused by these strains measured [27, 29, 40, 41]. There are at least three variants, dependent on the relative ductilities of film and substrate.

When the substrate is ductile, strain can be introduced into the film by deforming the substrate [28, 40-43]. The multistrain and sphere impression tests exemplify this approach (Fig. 5). In such tests, the strains can be imposed precisely and measured accurately. Accordingly, the methods rely on the ability to detect and measure the dimensions of the interface decohesions. Surface displacements comprise the basis for these measurements. This information is obtained by using either optical interference or profilometry [40,41]. The greatest precision can be realized when the film is optically translucent, because of large changes in reflectivity at separated (relative to bonded) interfaces.

Adhesion measurements for films on brittle substrates are more challenging. A strain energy density sufficient to decohere the interface can be provided by depositing an adherent layer onto the film, with sufficient intrinsic strain and thickness to achieve the required energy densities. This approach has been referred to as the superlayer test [Fig. 6(a)]. Otherwise, localized strains can be generated 
(a)

\section{MULTISTRAIN TEST}

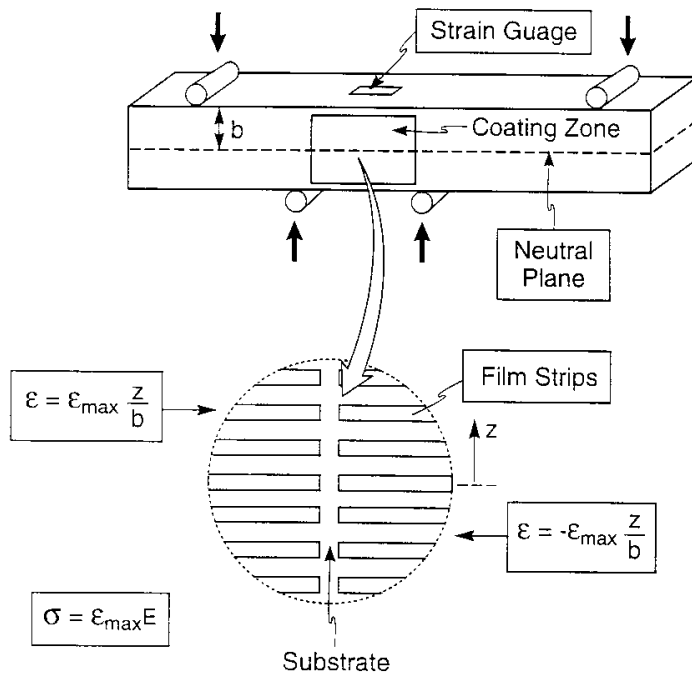

(b)

\section{SPHERE IMPRESSION TEST}

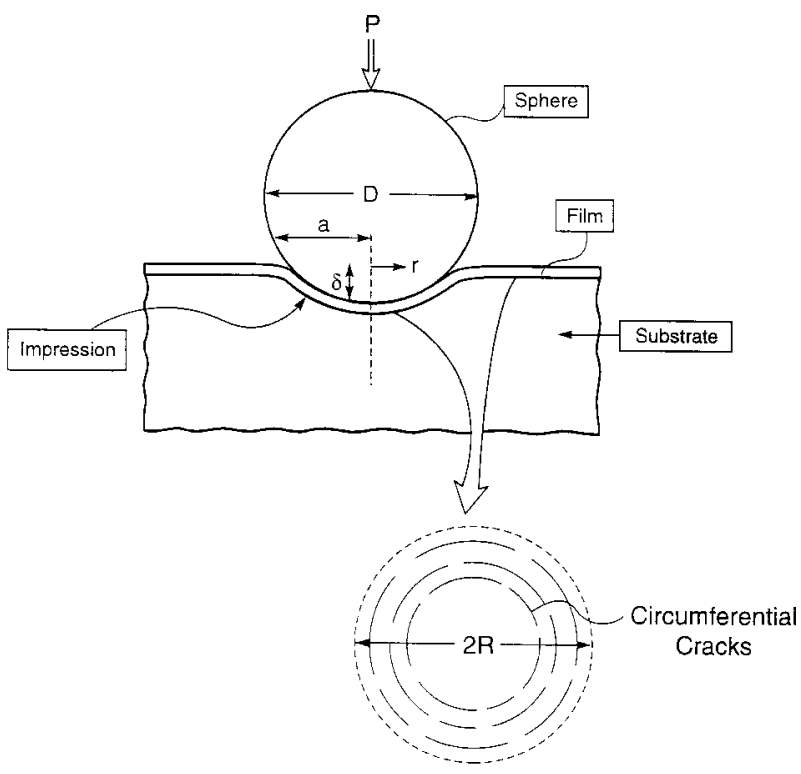

Fig. 5. Tests used to measure the toughness of interfaces between thin films and a ductile substrate: (a) multistrain test; (b) sphere impression test.

by indenting or scratching the film [27] [Fig. 6(b)]. In both cases, the difficulties in quantification concern calibration of the strain in the film. Progress has been made through various measurement and analysis methods [27, 44, 45].

\section{RUPTURE MECHANISMS}

\subsection{Generalities}

The largest body of quantitative information about mechanisms has been gained from metal/ 

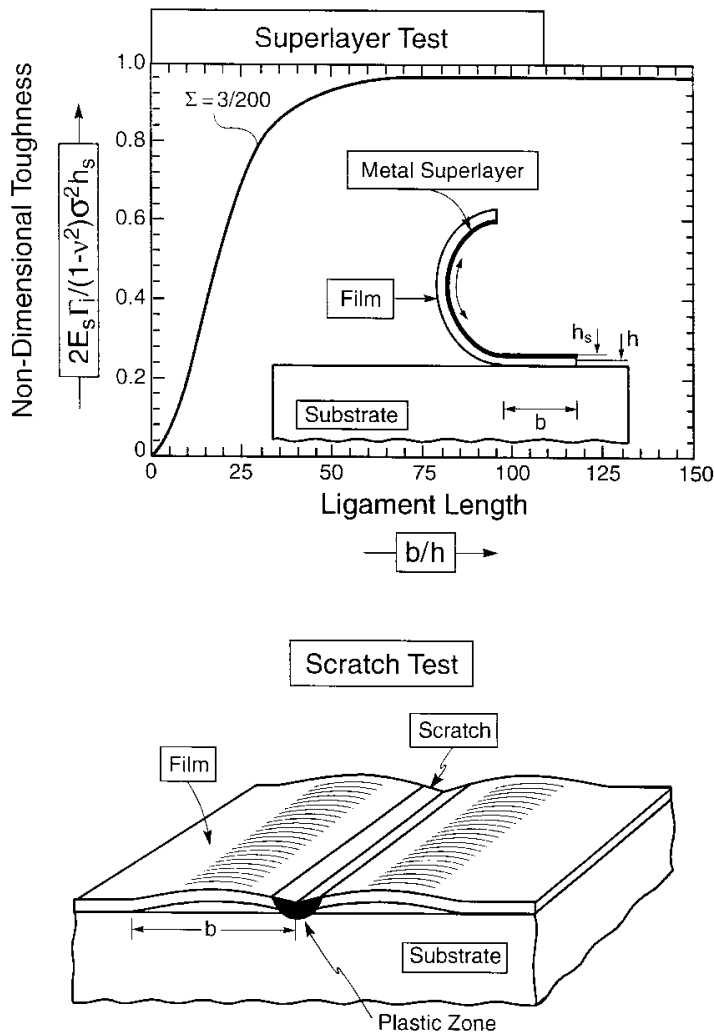

Fig. 6. Methods for measuring the interface adhesion between thin films and brittle substrates: (a) superlayer test; (b) scratch test.

oxide interfaces $[18,19,25,35,36,46-50]$. The associated measurements and observations are the principal basis for the following assertions, mostly made on interfaces between sapphire and polycrystalline metals (Fig. 7 and Table 1). A detailed analysis is given in Section 7 .

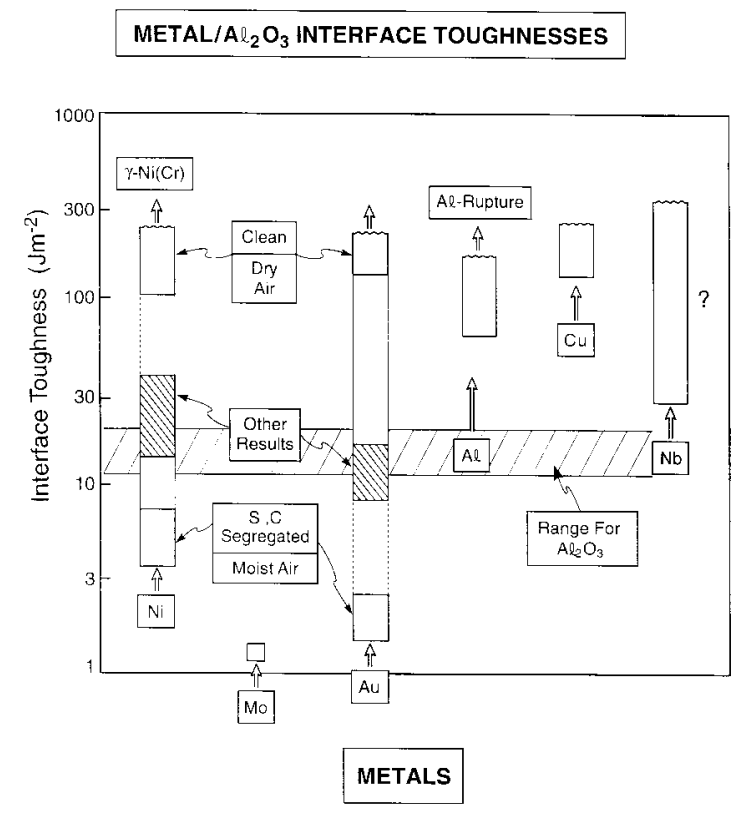

Fig. 7. The range of toughnesses found between $\mathrm{Al}_{2} \mathrm{O}_{3}$ and various metals. Note that many results reside in discrete domains that depend on "cleanliness". Only interfaces with Mo are consistently brittle. The question mark against the $\mathrm{Nb} / \mathrm{Al}_{2} \mathrm{O}_{3}$ system pertains to the invalid method used to ensure the toughness (see Table 1).

(i) Clean interfaces devoid of reaction products are inherently tough and ductile. The most vivid manifestation comprises crack blunting (Figs 8 and 9), which has been documented for interfaces with $\mathrm{Ni}[20,50], \mathrm{Au}[35,36], \mathrm{Cu}[49], \mathrm{Al}[25,51]$ and $\mathrm{Nb}[47,48]$. Such high adhesion is realized even though the metals are polycrystalline and non-epitaxial: that is, despite the interfaces being either incoherent or subject to a high density of misfit dislocations. However, only measurements

Table 1. Summary of experimental measurements

\begin{tabular}{|c|c|c|c|c|}
\hline \multirow[t]{2}{*}{ Bond category } & \multicolumn{2}{|c|}{ Materials } & \multirow[t]{2}{*}{ Toughness $\left(\mathrm{J} / \mathrm{m}^{2}\right)$} & \multirow[t]{2}{*}{ Condition } \\
\hline & Oxide & Metal & & \\
\hline \multirow[t]{12}{*}{ I. Mesoscale diffusion bonded interfaces } & $\mathrm{Al}_{2} \mathrm{O}_{3}$ & $\mathrm{Au}$ & $\sim 250^{\mathrm{a}}[19]$ & "Clean", dry air \\
\hline & & & $10[35,36]$ & Moist air \\
\hline & & $\mathrm{A} 1$ & $>100^{\mathrm{a}}[51,52]$ & $\begin{array}{l}\text { C infused } \\
\text { All invariably tough }\end{array}$ \\
\hline & & $\mathrm{Ni}$ & $5-8[54]$ & Segregated S \\
\hline & & & $10-40[20,54]$ & Moist air \\
\hline & & & $>100^{\mathrm{a}}[20]$ & Low S, dry environment \\
\hline & & $\gamma-\mathrm{Ni}(\mathrm{Cr})$ & $>300^{\mathrm{a}}[50]$ & Moist air, commercial alloy \\
\hline & & $\mathrm{Cu}$ & $120-250^{\mathrm{a}}[49]$ & Moist air \\
\hline & & Mo & $\sim 2$ & Invariably brittle \\
\hline & & $\mathrm{Nb}$ & $>200^{\mathrm{b}}$ & Single crystal \\
\hline & & & $\begin{array}{c}20 \\
\sim 20^{\mathrm{b}}\end{array}$ & $\begin{array}{c}\text { Moist air } \\
\text { Ag segregant }\end{array}$ \\
\hline & $\mathrm{SiO}_{2}$ & $\mathrm{Cu}$ & 20 & $\mathrm{Cr}$ adhesion layer \\
\hline \multirow[t]{3}{*}{ II. Deposited thin films } & $\mathrm{SiO}_{2}$ & $\mathrm{Cu}(\mathrm{Cr})$ & $10[9]$ & Moist air \\
\hline & & $\mathrm{Cu}$ & $\sim 2[9]$ & Moist air \\
\hline & DLC & Steel & $>100^{\mathrm{a}}$ & $\mathrm{Cr}$ adhesion layer \\
\hline III. Thin scales & $\mathrm{Al}_{2} \mathrm{O}_{3}$ & $\mathrm{Ni}(\mathrm{Al})$ alloy & $\sim 5[85]$ & Moist air \\
\hline
\end{tabular}

${ }^{\mathrm{a}}$ Crack blunting with opening displacements of the order of $1 \mu \mathrm{m}$.

${ }^{\mathrm{b}}$ Invalid toughness measurements. 
STATIONARY CRACK PROFILES

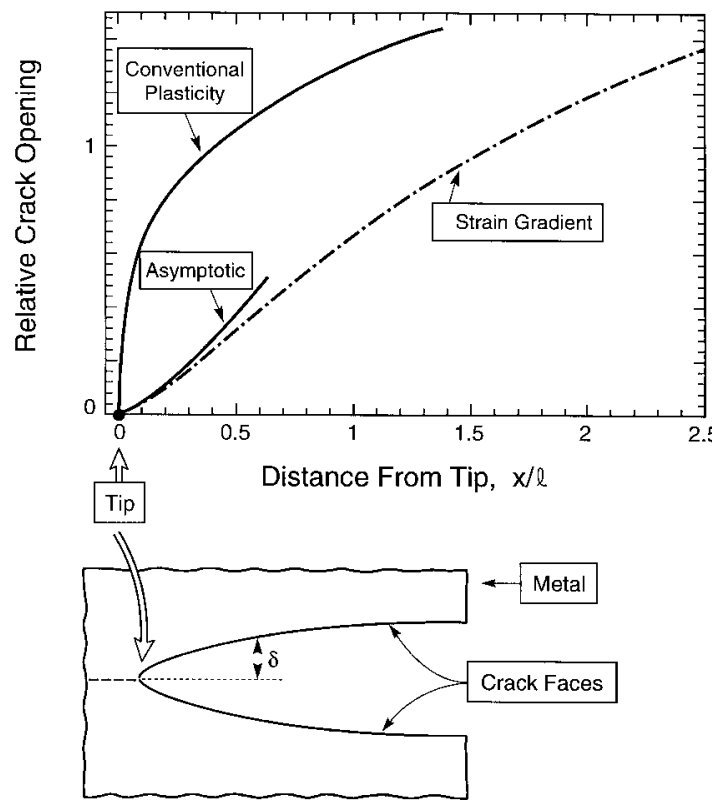

Fig. 8. Simulations of crack profiles with and without the plasticity length scale.

for $\mathrm{Al}$ systems indicate consistently tough, ductile interfaces [25, 51, 52]. Broad toughness ranges have been cited for $\mathrm{Ni}, \mathrm{Cu}, \mathrm{Au}, \mathrm{Pt}, \mathrm{Nb}$ bonded with $\mathrm{Al}_{2} \mathrm{O}_{3} \cdot \uparrow$ Most of these interfaces have been made with insufficient consideration given to the avoidance of contaminants and segregants. The cleanliness levels needed to achieve strong, stable interfaces may be provided in two ways. (a) By using rigorous processing practices that exclude contaminants during bonding. (b) By introducing alloying elements that "getter" contaminants and segregants into precipitates: $\mathrm{Cr}$ and $\mathrm{Ti}$ often perform these functions.

(ii) The role of contaminants and segregants is best demonstrated by beginning with a clean interface and systematically infusing a contaminant [19]. When this is done, weakening is often (though not always) found (Fig. 9). The presence of moisture in the testing environment exacerbates weakening in some cases $(\mathrm{Ni}, \mathrm{Au})$ by causing stress corrosion [19, 35, 36, 54]. The cracks typically propagate in accordance with a resistance curve, subject to steady-state toughnesses in the range $2-20 \mathrm{~J} / \mathrm{m}^{2}$. Adhesion energies when in this range, are found to be the source of practical problems. Even within this relatively narrow adhesion range, more than one mechanism seems to be involved (Fig. 1). In some instances, cracks

$\dagger$ Other materials, such as $\mathrm{Ti}$, result in reaction products that control the toughness [53]. blunt before they abruptly extend and then arrest. In others, the cracks remain sharp (at optical resolutions) and grow stably. The implication is that a variety of mechanisms exist, comparable in scope to those found in homogeneous materials. In this article, the three mechanisms depicted on Fig. 1 will be described and analyzed (Section 5). Small scale plastic yielding is invoked in each of the models employed, wherein plasticity is assumed to be confined to a zone that is small compared to the crack length.

One of the remarkable findings about oxide/metal interfaces is that, when clean, the energy release rates $G$ achieved without causing failure are well in excess of the critical energy release rate for the oxide [19, 48-51]. There are now several examples wherein $200-400 \mathrm{~J} / \mathrm{m}^{2}$ has been imposed on metal/ sapphire interface cracks without failure, despite a much smaller critical valve for the oxide, $\Gamma_{\text {oxide }} \approx$ $10-20 \mathrm{~J} / \mathrm{m}^{2}$. Eventually, failure does occur, but either by brittle cracking in the oxide or by ductile fracture in the metal rather than by separation of the interface. Such findings reinforce the assertion that metal/oxide interfaces are inherently strong. The interface crack blunts by plastic flow in the metal, resulting in the elimination of very high stress concentrations. The stress is no longer sufficient to activate failure mechanisms that would, otherwise, be present at a sharp interface crack. New mechanisms need to be activated (Fig. 1).

Accordingly, interface crack growth can be categorized in the manner illustrated on Figs 1 and 2. Three basic mechanisms are portrayed. All others are regarded as sub-categories of these three. Two features distinguish the models: (a) atomically-sharp relative to blunt cracks; (b) stationary relative to steady-state cracks. The consequences are described in Section 8.

\subsection{Optical observations}

When tests are conducted on metal/oxide interfaces, direct observations of the fracture mechanism can often be made, because of the transparency of the oxide $[19,35,36,49,50]$. Such observations have been conducted on interfaces involving $\mathrm{Al}_{2} \mathrm{O}_{3}$ with $\mathrm{Au}, \mathrm{Ni}$ and $\mathrm{Cu}[19,35,36,49,50]$. In all cases, when the interfaces are clean and tough, the optical constrast along the crack front reveals blunting prior to crack extension: as also validated by fringe measurements [20]. However, the occurrence of other features that characterize the fracture mechanism differs among the three interfaces. For interfaces with $\mathrm{Au}$ there is clear evidence of debond patches forming ahead of the blunt crack (Fig. 10) at $G$ levels significantly below the toughness $[19,35$, 36]. These debond domains plastically deform the $\mathrm{Au}$ and eventually coalesce to cause crack growth. Such features are representative of a process zone 


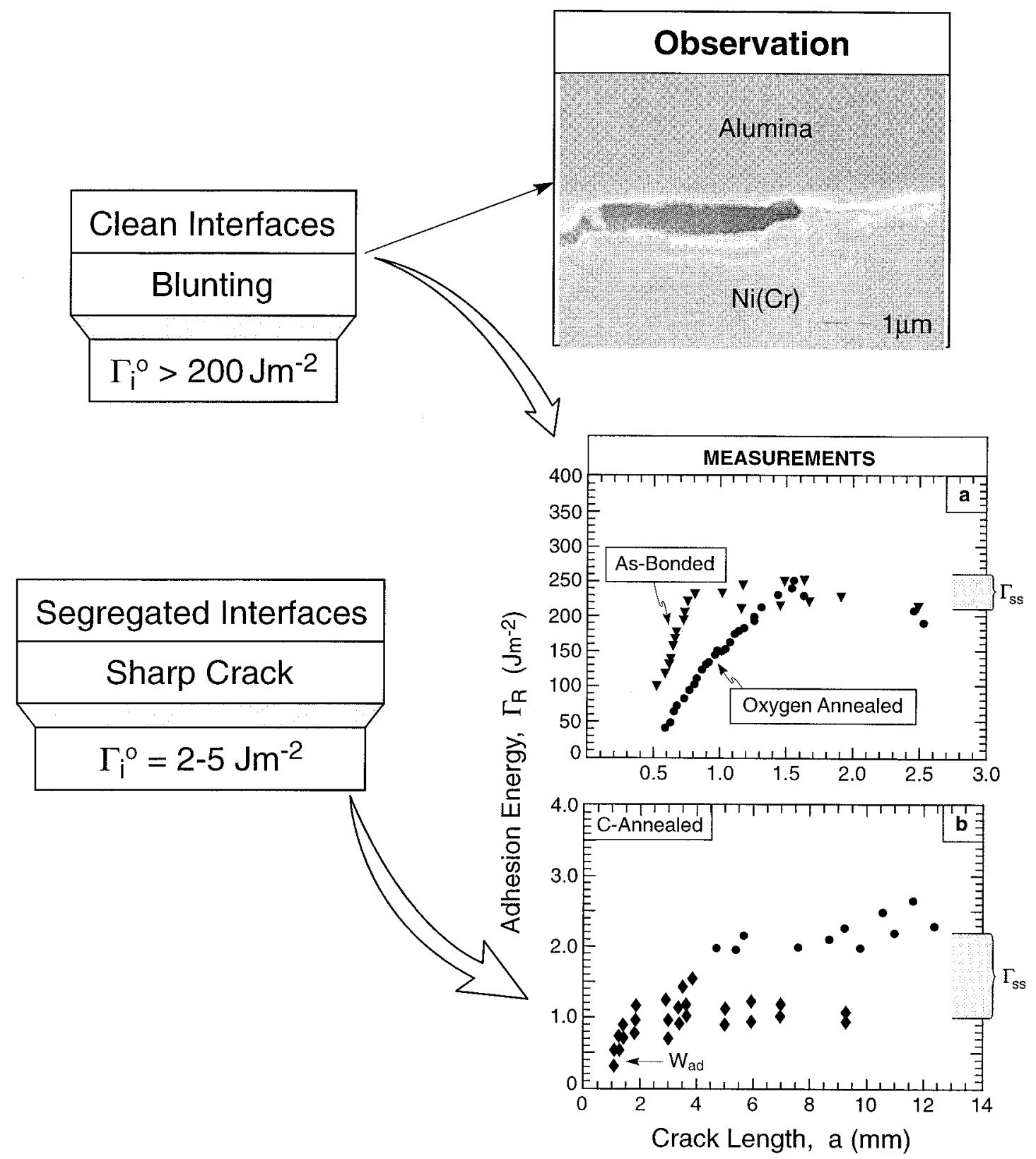

Fig. 9. Resistance curves for the $\mathrm{Au} / \mathrm{Al}_{2} \mathrm{O}_{3}$ interface measured in a dry environment: (a) clean interface; (b) interface infused with $\mathrm{C}[19]$. Also shown is the crack blunting that accompanies (a).

mechanism (mechanism II in Fig. 1). For interfaces with Ni, similar effects have been found [20].

When the interfaces have much lower toughness (of order $10 \mathrm{~J} / \mathrm{m}^{2}$ ), the cracks appear sharp at optical resolutions, suggestive of mechanism I in Fig. 1. In the crack wake, there are features indicative of plastic slip in the metal [36, 54], which are effectively characterized by atomic force (AFM) and scanning electron (SEM) microscopies.

Cracks have been observed to interact with precipitates present at the interface [49]. In some cases, they are attracted to the precipitates resulting in weakening (e.g. $\mathrm{Cu}_{2} \mathrm{O}$ in $\mathrm{Cu} / \mathrm{Al}_{2} \mathrm{O}_{3}$ and $\mathrm{FeAl}_{3}$ in
$\left.\mathrm{Al} / \mathrm{Al}_{2} \mathrm{O}_{3}\right)$. In others, the precipitates act as obstacles to crack growth, resulting in classical crack bowing and toughening (e.g. $\mathrm{CuAl}_{2} \mathrm{O}_{3}$ in $\mathrm{Cu}$ / $\mathrm{Al}_{2} \mathrm{O}_{3}$ ). These second-order effects have yet to be thoroughly explored.

\subsection{Atomic force microscopy}

Plastic deformation occurring upon interface crack growth and its role in governing mechanisms is manifest as topographical features on the metal fracture surface that can be characterized by AFM (Fig. 11) [36, 54]. At interfaces having moderate toughness $\left(20-50 \mathrm{~J} / \mathrm{m}^{2}\right)$ periodic blunting steps hav- 

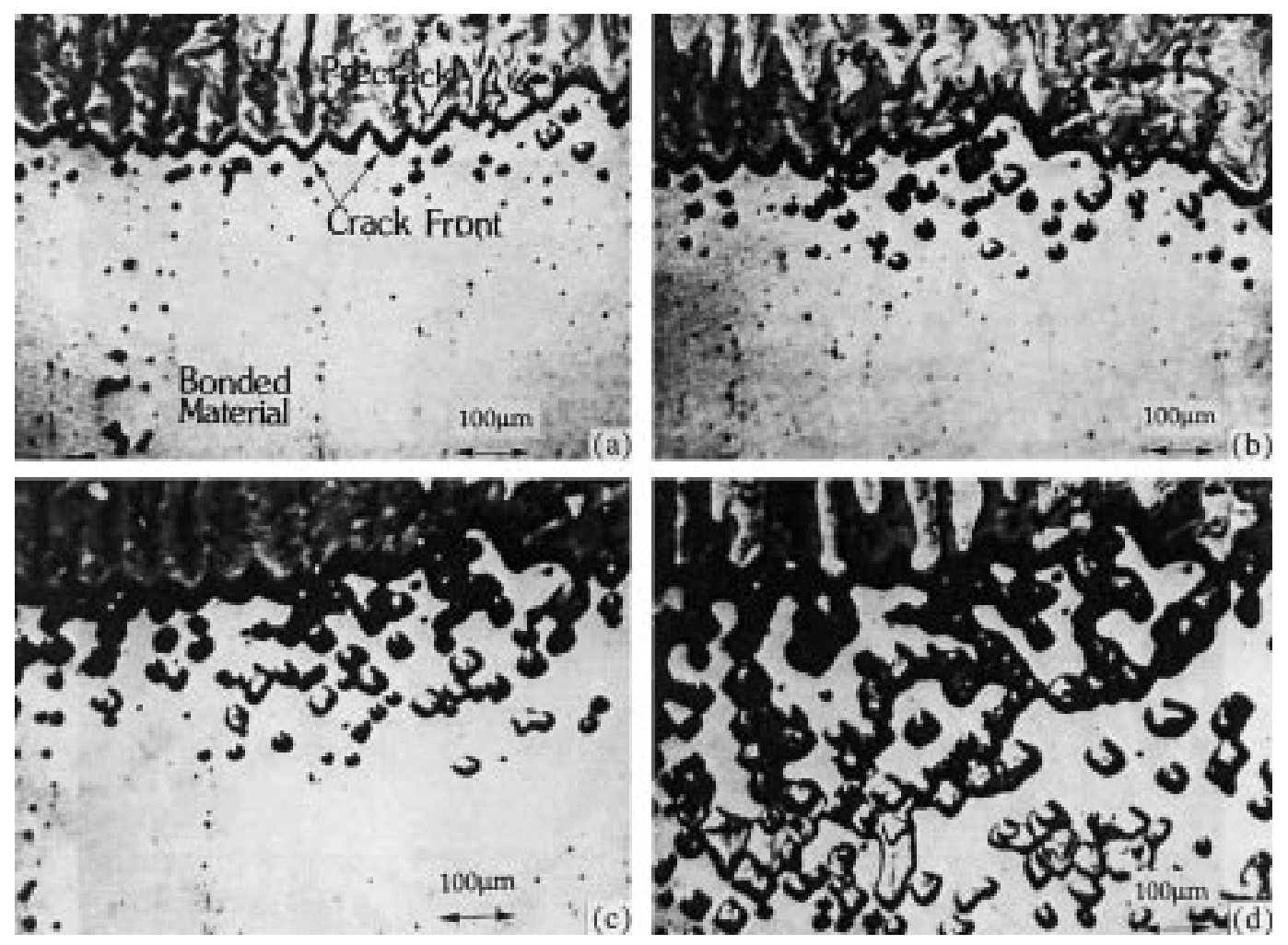

Fig. 10. Optical plan views of crack growth at a "clean" $\mathrm{Al}_{2} \mathrm{O}_{3}$ tested in a dry environment [36]. The energy release rate increases from (a) to (d). Crack growth occurs at (d).

ing heights $0.5-1 \mu \mathrm{m}$ are evident in conjunction with a high density of intervening slip steps, each $0.5-2 \mathrm{~nm}$ in height, separated by $10-100 \mathrm{~nm}$. The slip lines often emanate from debond sites ahead of the crack. Mechanism II or III (Fig. 1) is implied. At lower toughnesses $\left(10-20 \mathrm{~J} / \mathrm{m}^{2}\right)$ slip steps are still apparent, but blunting steps are either absent or sufficiently infrequent that they are difficult to detect, indicative of mechanism I (Fig. 1). Brittle interfaces $\left(1-5 \mathrm{~J} / \mathrm{m}^{2}\right)$ provide no indications of plasticity at AFM resolutions. At the highest toughnesses $\left(>200 \mathrm{~J} / \mathrm{m}^{2}\right)$, plasticity features indicative of ductile rupture in the metal are often found, particularly at interfaces with low yield strength metals. These comprise necked ridges with a classical ductile/dimple appearance in accordance, with mechanism III (Fig. 1) [52].

\subsection{Stress corrosion}

A basic, unexplained finding is that some interfaces are susceptible to stress corrosion in the presence of moisture, while others are not. Those that exhibit stress corrosion include $\mathrm{Au}$ and $\mathrm{Ni}[19,20$, $35,36,54]$. Various interfaces in microelectronic structures are also susceptible to stress corrosion [55-57]. Those insensitive to moisture include $\mathrm{Al}$ [51], $\mathrm{Cu}$ [49], Pt [58]. The former must be tested in a dry environment to reveal intrinsic fracture mechanisms. It may be significant that the stress cor- rosion susceptible interfaces are also the ones that exhibit strong segregant embrittlement.

\section{MECHANICS OF INTERFACE CRACKS}

Much has been written about the mechanics of interface cracks $[1,2,6,8,10]$ and only a brief summary seems warranted in this article. There are two fundamentally important factors about interfaces that differ from homogeneous materials.

(i) The elastic property mismatch causes the energy release rate, $G$, and the mode mixity angle, $\psi$, to differ from those found for homogeneous bodies subject to the same loading. These differences are well established and fundamentally related to the first Dundurs' parameter [2]:

$$
\alpha_{\mathrm{D}}=\frac{\bar{E}_{1}-\bar{E}_{2}}{\bar{E}_{1}+\bar{E}_{2}}
$$

where $\bar{E}$ is the plane strain Young's modulus. The subscripts 1 and 2 refer to the two adjoining materials.

(ii) Unlike isotropic solids, cracks may extend along interfaces when the loading is not mode I (i.e. $\psi \neq 0$ ). Accordingly, the fracture toughness must be specified as a function of $\psi$. A useful phenomenological relation is [2]:

$$
\Gamma_{i} / \Gamma_{i}^{0}=1+\tan ^{2}(1-\lambda) \psi
$$



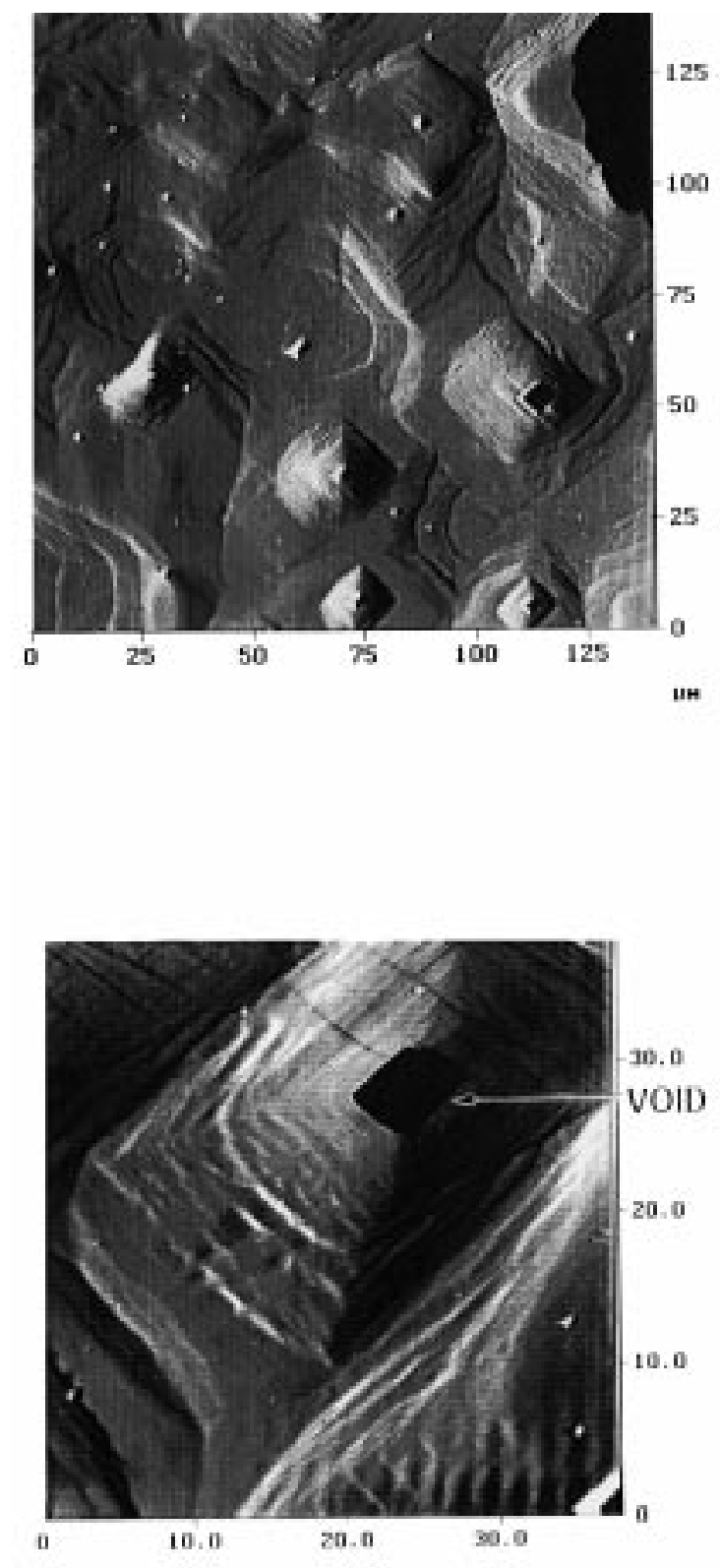

Fig. 11. AFM images of a $\mathrm{Au}$ fracture surface from the specimen shown in Fig. 10 revealing slip steps emanating from initial voids in the $\mathrm{Au}$ at the interface.

where $\Gamma_{i}^{0}$ is the mode I toughness and $\lambda$ is a coefficient that reflects the interface roughness, as well as the plasticity in the adjoining materials. There is no mixed-mode effect if $\lambda=1$, but a strong dependence exists when $\lambda$ is small.

\section{ADHESION PARAMETERS}

\subsection{The length scales}

Interface fracture phenomena have been approached from two directions. In a complete

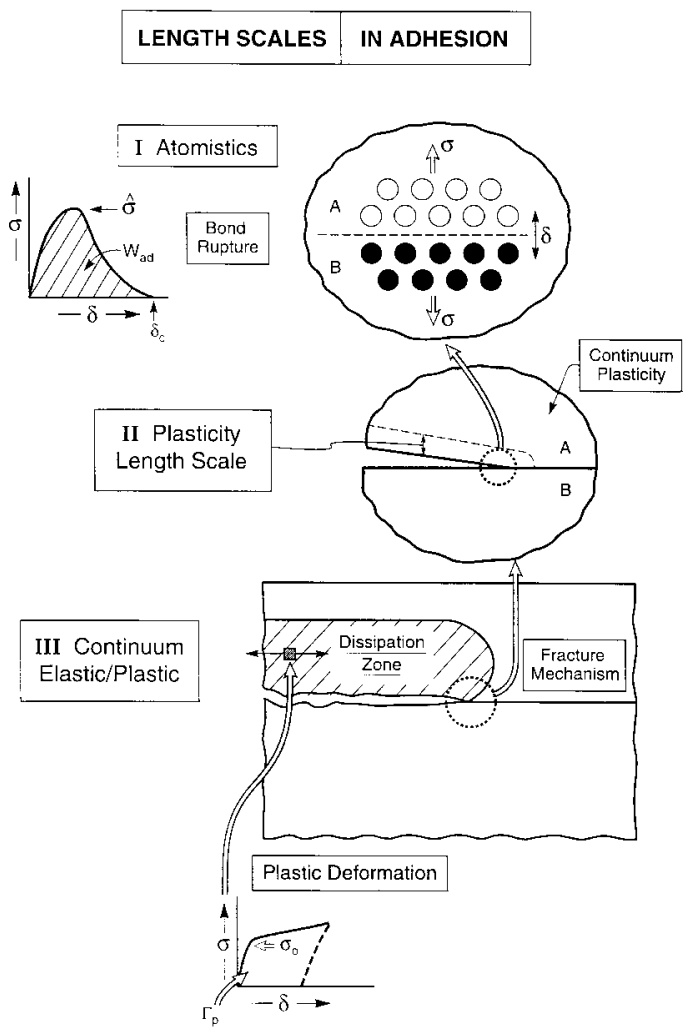

Fig. 12. A schematic illustrating the zones of inelastic deformation that occur around interface cracks, with associated length scales.

description these should converge at the appropriate scale (Fig. 12).

(i) Atomic level. A mechanism of crack growth must be asserted and calculations relevant to that mechanism performed using first principles methods [59-62]. It is believed that calculations involving several thousands of atoms with periodic boundary conditions provide useful information. It is necessary to determine the effect of tensile stress $\sigma$ applied normal to the interface on the separation of the atoms across the interface, $\delta$, up to the point of rupture, $\delta_{\mathrm{c}}$ (Figs 12 and 13). The two parameters needed to connect these calculations up to larger length scales are the thermodynamic work-of-adhesion, $W_{\text {ad }}$ and the peak stress (or bond strength) $\hat{\sigma}$. Available results (Fig. 13) indicate quite large $\hat{\sigma}$ for essentially all clean, lattice-matched metal/oxide interfaces: $\sigma \approx 10 \mathrm{GPa}$. That such interfaces should have high strength is consistent with experimental findings noted in Section 3. The high stresses are expected to induce inelastic/plastic deformation when one of the adjoining materials is either a metal, intermetallic or thermoplastic.

Connections between atomistic calculations and practical adhesion problems require that the influences of defects and segregants be addressed. Initial determinations of segregant 


\section{FIRST PRINCIPLES CALCULATIONS}

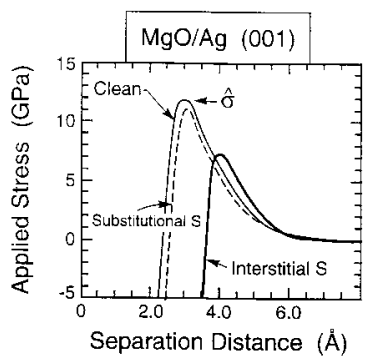

\begin{tabular}{|l|c|}
\hline \multicolumn{2}{|c|}{ Work Of Adhesion $\left(\mathrm{Jm}^{-2}\right)$} \\
\hline \hline $\mathrm{MgO} / \mathrm{Al}$ & 0.95 \\
\hline $\mathrm{MgO} / \mathrm{S}_{\mathrm{int}} / \mathrm{Al}$ & 0.37 \\
\hline $\mathrm{MgO} / \mathrm{S}_{\mathrm{sub}} / \mathrm{Al}$ & 0.75 \\
\hline
\end{tabular}

Fig. 13. Some of the first principles calculations for metal oxide interfaces indicating the effect of $\mathrm{S}$ segregation and the stress/displacement relations.

effects have been made (Fig. 13), which reveal some of the effects implied by the experimental work. Namely, an increase in the equilibrium spacing of host atoms across the interface (highlighted on Fig. 13) reduces the work-ofseparation and, in most cases, the peak stress. These studies are quite preliminary in nature, but suggest directions for further calculations. The new variables that need to be addressed include various defects, such as misfit dislocations and non-basal orientations of the oxide, as well as more systematic studies of segregants.

(ii) Continuum level. The stresses and displacements further from the crack must be consistent with those expected from the loads and the continuum level elastic/plastic field. This representation becomes inappropriate close to the crack, because of the length scale effects involved in plasticity [21-23]. One goal is to introduce this length into numerical schemes and to bring this formulation as close to the crack tip as dislocation dynamics allow. This scale is not yet known. But the results from micro-indentation analysis suggest that lengths at least as small as $0.1 \mu \mathrm{m}$ can be addressed using this approach [63-67]. It has still to be ascertained whether yet another inelastic constitutive law is needed even closer to the crack tip.

\subsection{The parameters}

All interface models (Figs 1 and 2) have basic analogies with their homogeneous counterparts. These analogies facilitate specification of parameters that characterize adhesion. Two underlying features provide perspective.

(i) Resistance curves often arise (Fig. 2), because of the energy dissipated behind the crack. The phenomenology is directly comparable to that found in metals, ceramics and composites [68-72]. Accordingly, there is an initiation toughness, $\Gamma_{\mathrm{c}}$, and a steady-state toughness, $\Gamma_{\text {ss }}$ (Figs 2 and 8).

(ii) A brittle-to-ductile transition arises when the maximum realizable stress in the plastic zone becomes too small to reach the stress needed to activate the rupture mechanism (Figs 1 and 2). The most direct analogy is with the brittle-toductile transition in steels [13, 14]. The parameters to be used should be capable of expressing this transition.

Based on these considerations, at least five parameters are needed to characterize the engineering adhesion, beyond basic elastic constants. Three parameters characterize each adjoining material. One is the yield strength, $\sigma_{0}$. Another is the strain hardening coefficient, $N$. A plasticity length scale is also required: otherwise the stresses near the crack would never attain the level needed to rupture the interface (Section 6). This length scale $\ell$ comprises the third parameter.

Two parameters characterize the interface: the work-of-adhesion $W_{\text {ad }}$ and an interface "strength", designated $\hat{\sigma}$, as defined on Fig. 1.

Combining these parameters to form non-dimensional indices facilitates presentation and helps compare and contrast models. There are four such indices (Fig. 2).

(i) An adhesion (or toughness) index: $\Gamma_{i} / \Gamma_{0}$, with $\Gamma_{i}$ the adhesion and $\Gamma_{0}$ the energy consumed in the fracture process zone. Typically, $\Gamma_{i}$ differs for initiation $\Gamma_{\mathrm{c}}$ and steady state, $\Gamma_{\mathrm{ss}}$. For an atomically sharp crack, $\Gamma_{0} \equiv W_{\text {ad }}$. Otherwise, $\Gamma_{0}$ is larger.

(ii) An interface strength index; $\hat{\sigma} / \sigma_{0}$, with $\hat{\sigma}$ the peak stress characterizing the rupture mechanism (see Figs 1 and 12). For fracture by bond rupture, $\hat{\sigma}$ is the theoretical strength, possibly altered by interface segregants. For other mechanisms, $\hat{\sigma}$ is smaller.

(iii) The plasticity length scale index: $\ell / R_{0}$, with $R_{0}$ being a scaled plastic zone size

$$
R_{0}=E \Gamma_{0} /\left[3 \pi\left(1-v^{2}\right) \sigma_{0}^{2}\right]
$$

The role of this length scale will emerge in subsequent sections. It can be regarded as the size of the plastic zone under conditions wherein the applied energy release rate approaches $\Gamma_{0}$. The actual size of the plastic zone in small scale yielding is given by 


$$
R_{\mathrm{p}}=\left(\Gamma_{i} / \Gamma_{0}\right) R_{0} .
$$

(iv) The strain hardening coefficient, $N$.

By expressing the results of the models as plots of $\Gamma_{i} / \Gamma_{0}$ against $\hat{\sigma} / \sigma_{0}$, for various $N$ and $\ell / R_{0}$ (Fig. 2), the similarities and differences among the models become apparent. This comparison is made in Section 8.

\section{PLASTICITY LENGTH SCALE}

\subsection{The phenomenon}

Conventional plasticity is unable to describe the behavior found upon interface crack growth. The basic deficiency is that the stresses achieved near the crack never exceed those required to cause interface rupture. Accordingly, blunting develops in plasticity-based models [68] [see Fig. 8(b)] and interface rupture is precluded. Introduction of a plasticity length scale addresses this paradox [22]. In small volumes, subject to a large strain gradient, such as the crack tip, the stresses become appreciably larger than those achievable with conventional plasticity. This effect enables the stresses near the crack to reach the higher levels needed to cause rupture in the fracture process zone.

There is overwhelming experimental evidence that plastic flow is affected by strain gradients in the micrometer range. The manifestations include: effects of particle size on strain hardening in particle strengthened alloys [73], elevations in hardness at small penetration depths [63-67], and grain size effects in yielding [74]. None of these can be simulated with conventional theories of plasticity. By introducing a length in the plasticity formulation, it is now possible to explore size effects and provide interconnections with submicrometer level phenomena. Application of this concept to interface cracks provides the new opportunity addressed here.

Developments thus far, while phenomenological [21], indicate the need for two length scales. One characterizes the rotation gradients, $\ell_{\mathrm{R}}$, and the other stretch gradients, $\ell_{\mathrm{S}}$. From presently available experimental measurements, these scales differ by about a factor 10: with $\ell_{\mathrm{R}}=5 \mu \mathrm{m}$ and $\ell_{\mathrm{S}}=0.5 \mu \mathrm{m}$ [20-22, 63]. Both are relatively material insensitive, but may depend upon hardening (by strain or precipitation) [75]. The stretch length scale, $\ell_{\mathrm{S}}$, is most relevant to stress elevation effects around interface cracks.

\subsection{The constitutive law}

For purposes of numerical analysis, the phenomenological constitutive law for strain gradient plasticity expresses the effective strain $\varepsilon$ as:

$$
\varepsilon=\left\{\varepsilon_{\mathrm{e}}^{\mu}+\left(\ell_{\mathrm{S}}^{2} \eta_{i j k}^{(1)} \eta_{i j k}^{(1)}\right)^{\mu / 2}+\left[(2 / 3) \ell_{\mathrm{R}}^{2} \chi_{i j} \chi_{i j}\right]^{\mu / 2}\right\}^{1 / \mu}
$$

where $\ell_{\mathrm{S}}$ is the length scale for stretch gradients and $\ell_{\mathrm{R}}$ that for rotation gradients. The quantity $\eta_{i j k}^{(1)}$ is a measure of the second gradient of displacement and $\chi_{i j}$ the deformation curvature (rotation gradients). The equivalent strain is defined in the usual way in terms of the deviator $\varepsilon_{i j}^{\prime}$ by:

$$
\varepsilon_{\mathrm{e}}=\sqrt{(2 / 3) \varepsilon_{i j}^{\prime} \varepsilon_{i j}^{\prime}}
$$

The exponent $\mu$ is between 1 and 2, dependent on the interactions between the statistically-stored and geometrically-necessary dislocations [75, 76]. Full details are provided elsewhere [21, 63].

\subsection{Crack tip fields}

The length scale associated with stretching can have a dramatic effect on the stress and displacement fields around both stationary and steady-state cracks [Figs 14(a) and (b)] [22, 77]. The principal effects comprise a major elevation in the normal traction along the crack plane, ahead of the crack, accompanied by a corresponding reduction in the crack opening displacements (Fig. 8). Stress distributions calculated for a mode I crack in a homogeneous material in steady state [Fig. 14(a)] and for a stationary crack [Fig. 14(b)], illustrate the funda-
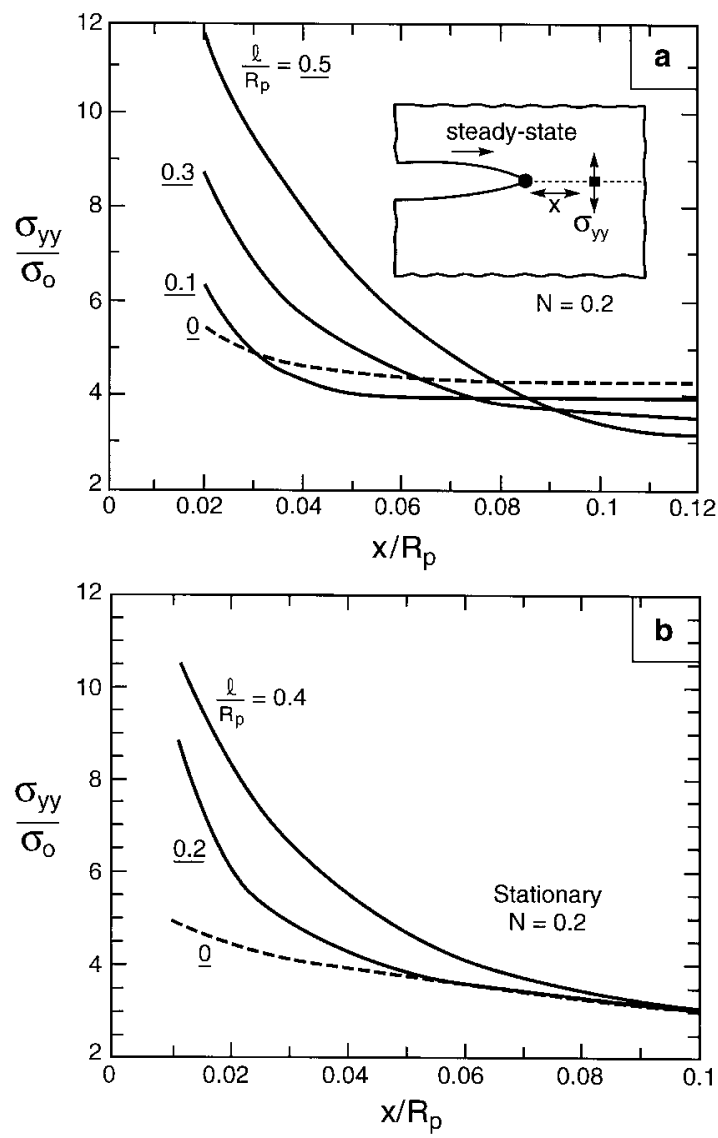

Fig. 14. Effects of the plasticity length scale on the stress fields arising on the plane ahead of a crack: (a) steadystate crack in a monolithic solid; (b) stationary crack at a bimaterial interface. 
mental characteristics. Near-tip fracture conditions have not been imposed on these small scale yielding solutions. The plastic zone size is the only length in the problem other than $\ell$. From equations (3) and (4), it is related to the applied energy release rate $G$ according to $R_{\mathrm{p}}=E G /\left[3 \pi\left(1-v^{2}\right) \sigma_{0}^{2}\right]$. In both cases, there is a dramatic elevation in $\sigma_{y y}$ as $\ell / R_{\mathrm{p}}$ increases, in the range $0-0.5$.

\section{SYNOPSIS OF MEASUREMENTS AND OBSERVATIONS}

There are relatively few measurements performed on metal/oxide or metal/inorganic interfaces that satisfy the rigorous dictates of valid fracture toughness (or adhesion energy) determinations. A summary is presented in Fig. 7 and Table 1. There are many other measurements, but in our opinion, either the measurement procedures or the energy release rate analysis are too deficient for the results to have validity sufficient for comparison with models.

The measurements are categorized according to the method used to generate the interface. The three categories are: (i) diffusion bonding, (ii) thin film deposition and (iii) oxide scale growth. Various comments in the table provide ancillary information about either the testing or the "cleanliness" of the interface, as well as the existence of "adhesion layers".

\subsection{Crack blunting}

A significant fraction of the tests (see footnote a in Table 1) exhibit extensive crack blunting with tip-opening displacements exceeding $1 \mu \mathrm{m}$. Each of these systems is able to sustain energy release rates larger than $100 \mathrm{~J} / \mathrm{m}^{2}$ without rupturing the interfaces. These systems comprise $\mathrm{Al}_{2} \mathrm{O}_{3}$ bonded to $\mathrm{Al}$ $[51,52], \gamma-\mathrm{Ni}(\mathrm{Cr})[50], \mathrm{Cu}[49]$, and $\mathrm{Nb}[47,48]$, as well as $\mathrm{Ni}[20,54]$ and $\mathrm{Au}[19,35,36]$ (clean in dry air). When these systems fail, the rupture may occur in one of the adjoining materials rather than at the interface. For example, at the interface with $\gamma-\mathrm{Ni}(\mathrm{Cr})$, cracks diverge into the sapphire. In bonds with $\mathrm{Al}$ and $\mathrm{Au}$, eventual failure occurs by plastic hole evolution in the metal. In the former, this happens entirely in the metal, in accordance with a classical ductile fracture mechanism, except that the interface provides a relatively high number density of hole nucleation sites [51]. In the latter, the interface debonds before the holes coalesce by plastic flow.

It is asserted that such behavior is representative of essentially all metal/oxide interfaces devoid of contaminants and segregation. That is, clean interfaces are strong and tough. The challenge is to explain why other metal/oxide interfaces have considerably lower toughness. These lower toughness interfaces are present subject to two basic categories: (i) those involving thin films; (ii) interfaces that are either contaminated or have "uncontrolled" levels of cleanliness. The following assessment examines these two categories.

\subsection{Thin film interfaces}

Interfaces between thin films and thick substrates mostly have interface toughnesses in the range 2 $5 \mathrm{~J} / \mathrm{m}^{2}[9,27,29,40-42,44]$. This toughness range seems to apply both when the film is ductile (such as $\mathrm{Cu})[9,29]$ and the substrate brittle, and vice versa. It is surmised that, in such cases, the interface cracks remain atomically sharp. These inferior toughnesses are appreciably enhanced upon use of a thin "adhesion layer". Such layers comprise either $\mathrm{Cr}$ or Ti. Their presence typically increases the adhesion energy by about a factor of 10 [9].

Two different phenomena would appear to be involved in the low adhesion in the absence of $\mathrm{Cr}$ or Ti.

(i) A scale effect associated with the thinness of the films. That is, the extent of plastic deformations in the metal is restricted to a zone related to film thickness [5]. This is exacerbated by the plasticity length scale which becomes more prominent within the smaller plastic zones.

(ii) The materials and fabrication strategies commonly used with thin film systems results in a susceptibility to interface contamination or segregation. The benefit provided by $\mathrm{Cr}$ or $\mathrm{Ti}$ adhesion layers appears to derive from their ability to "getter" contaminants (particularly C) and, thereby, inhibit segregant embrittlement.

Work concerning $\mathrm{Al}_{2} \mathrm{O}_{3}$ thin layers formed on $\mathrm{Ni}$ based substrates by oxidation indicates a key role of segregants, particularly $\mathrm{S}$ (and perhaps C) [54, 78-80]. These elements are present in the alloy at relatively low initial levels (a few p.p.m.). However, during oxidation, they diffuse readily to the oxide/ metal interface and segregate with sufficient local concentration to cause embrittlement.

\subsection{Segregants and contaminants}

There are many intermediate (system specific) findings involving blunt and sharp cracks having fracture energies in the $2-20 \mathrm{~J} / \mathrm{m}^{2}$ range, dependent on the method for generating the interface and the moisture content in the test atmosphere, as well as the chemical nature and extent of segregants.

In most cases, the key variables have neither been carefully documented nor precisely controlled, resulting in an inability to relate toughness levels to any single factor. However, the authors are aware of two (possibly three) studies sufficiently well controlled to reach meaningful conclusions.

Ultraclean $\mathrm{Al}_{2} \mathrm{O}_{3} / \mathrm{Au}$ interfaces tested in a dry environment have high toughness $>250 \mathrm{~J} / \mathrm{m}^{2}$ [19]. Infusion of $\mathrm{C}$ into these same interfaces reduces the toughness to $2 \mathrm{~J} / \mathrm{m}^{2}$ (Figs 7 and 9). This happens without changing the yield strength of the Au. The 
Table 2. Material properties for selected interfaces. $\ell_{\mathrm{R}} \approx 5 \mu \mathrm{m}, \ell_{\mathrm{S}} \approx 0.5 \mu \mathrm{m}$. Results in parentheses are estimates based on bulk material properties with equivalent microstructure and purity

\begin{tabular}{|c|c|c|c|c|c|c|}
\hline $\begin{array}{l}\text { System } \\
\text { oxide }\end{array}$ & Metal & $\bar{E}_{1}(\mathrm{GPa})$ & $\bar{E}_{2}(\mathrm{GPa})$ & $\sigma_{0}(\mathrm{MPa})$ & $W_{\text {ad }}\left(\mathrm{J} / \mathrm{m}^{2}\right)[84]$ & $R_{0}(\mu \mathrm{m})^{\mathrm{a}}$ \\
\hline \multirow[t]{6}{*}{$\mathrm{Al}_{2} \mathrm{O}_{3}$} & $\mathrm{Au}$ & 400 & 100 & 50 [36] & $\begin{array}{l}0.59 \\
0.3^{\mathrm{b}}\end{array}$ & $\begin{array}{r}150 \\
2.5\end{array}$ \\
\hline & $\mathrm{Ni}$ & & 200 & 80 [20] & 0.72 & 3 \\
\hline & $\mathrm{Al}$ & & 70 & $40[51]$ & & 7 \\
\hline & $\gamma-\mathrm{Ni}$ & & 200 & $600[50]$ & - & $<1$ \\
\hline & $\mathrm{Nb}$ & & 108 & $250[78]$ & $0.8^{\mathrm{c}}$ & \\
\hline & $\mathrm{Cu}$ & & 120 & (50) & 0.54 & $\sim 5$ \\
\hline $\mathrm{SiO}_{2}$ & $\mathrm{Cu}$ & 100 & 120 & $(50)$ & & \\
\hline
\end{tabular}

$\mathrm{R}_{0}$ based on $\Gamma_{0} \equiv W_{\text {ad }}$

Reduced by $\mathrm{C}$ infusion [19].

${ }^{\mathrm{c}}$ Reduced to about $0.5 \mathrm{~J} / \mathrm{m}^{2}$ by Ag monolayer at interface [47, 48].

dramatic reduction in toughness must, accordingly, be attributed to the effects on the bonding of $\mathrm{C}$ segregated at the interface. This effect is manifested in a work-of-adhesion that diminishes upon $\mathrm{C}$ infusion from 0.6 to $0.3 \mathrm{~J} / \mathrm{m}^{2}$ (Table 2) [19]. There are also likely to be effects of segregated $\mathrm{C}$ on the bond strength, $\hat{\sigma}$.

A comparison of interface toughnesses has been made on $\mathrm{Al}_{2} \mathrm{O}_{3} / \mathrm{Ni}$ interfaces at differing $\mathrm{S}$ levels (Fig. 7) [54]. The $\mathrm{S}$ impurity content has been reduced to low (sub p.p.m.) levels by annealing in hydrogen. Interfaces made with $\mathrm{Ni}$ "purified" in this manner have toughnesses of the order of $30 \mathrm{~J} /$ $\mathrm{m}^{2}$. Conversely, interfaces made with as-received $\mathrm{Ni}$ have a toughness of only $5 \mathrm{~J} / \mathrm{m}^{2}$. This segregant effect is not as dramatic as that for $\mathrm{C}$ in $\mathrm{Al}_{2} \mathrm{O}_{3} / \mathrm{Au}$. It is surmised that a greater $\mathrm{S}$ effect could be demonstrated if all of the impurities in the $\mathrm{Ni}$ could either be removed or gettered. This should result in a "clean" interface toughness at the $300 \mathrm{~J} / \mathrm{m}^{2}$ level found for $\gamma-\mathrm{Ni} / \mathrm{Al}_{2} \mathrm{O}_{3}$ [50] [Figs 7 and 8(a), Table 1]. Then, reductions to $5 \mathrm{~J} / \mathrm{m}^{2}$, or lower, caused by $\mathrm{S}$ would be more dramatic. These findings are consistent with the effects of $\mathrm{S}$ on the adhesion to $\mathrm{Ni}$ alloys of thermally grown alumina [78-80].

A third illustration comprises metallic segregants at $\mathrm{Al}_{2} \mathrm{O}_{3} / \mathrm{Nb}$ interfaces [47, 48]. In this case, the testing protocol did not give valid toughness results. Valid tests [81] gave much lower toughnesses. Nevertheless, the relative changes are still regarded as meaningful. The basic effect comprises a factor 100 reduction in the toughness caused by a monolayer of Ag. There is an associated change in the work-of-adhesion from $0.8 \mathrm{~J} / \mathrm{m}^{2}$ for a "clean" interface to about $0.5 \mathrm{~J} / \mathrm{m}^{2}$ for interfaces with a monolayer of segregated $\mathrm{Ag}$.

\subsection{Yield strengths}

The plastic zone sizes are determined by measuring the yield strength of the metal layer either from curvature hysteresis upon heating and cooling of a trilayer $[82,83]$ or by performing tensile tests on thin, annealed metal layers or by microindentation [20, 35, 36] (Fig. 15). There are two complicating issues. (i) The metal microstructure changes upon diffusion bonding. It also develops texture and, sometimes changes chemistry by dissolving $\mathrm{Al}_{2} \mathrm{O}_{3}$ which may precipitation strengthen the metal. Accordingly, it is most relevant to measure $\sigma_{0}$ after bonding. In principle, the trilayer and indentation measurements account for these effects.

(ii) When the metal layer is thin, the plasticity length scale exerts its influence and, when attached to a substrate, causes the yield strength to increase, especially in the submicrometer range $[82,83]$.

The trilayer measurements are the least ambiguous. Such measurements indicate $\sigma_{0}$ within the range expected from bulk material measurements, given

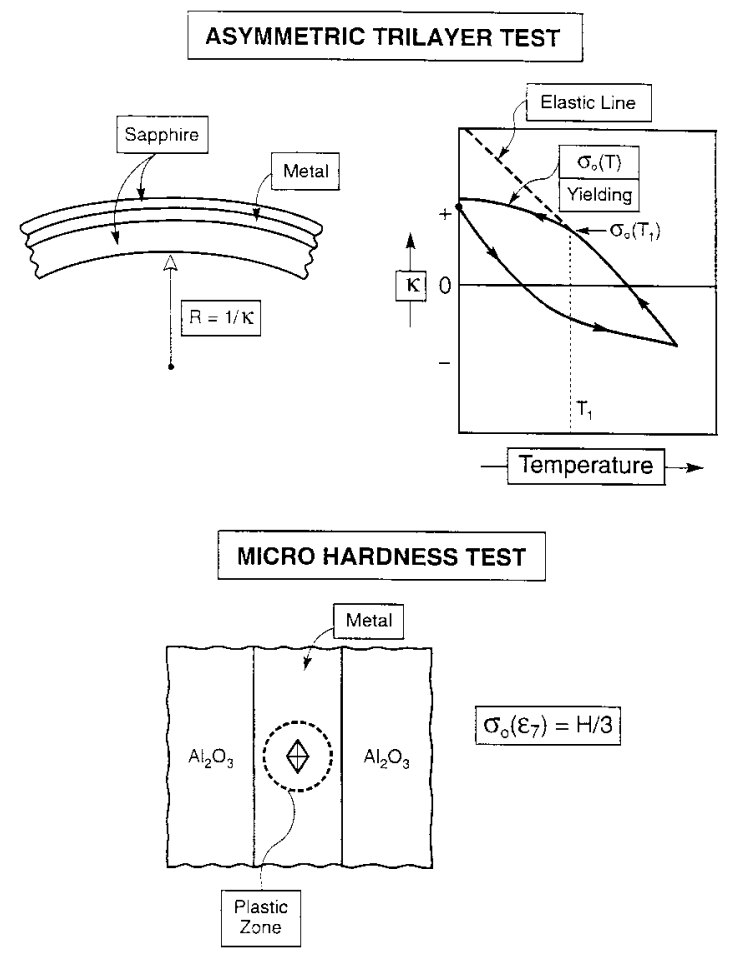

Fig. 15. Methods for measuring the yield strength of metals subsequent to bonding with oxides: (a) trilayer curvature; (b) microindentation. 
their chemistry and microstructure. Microindentation has, in some cases, inferred higher values [36]. This happens even though the indents are in a size range large enough for the plasticity length scale to be unimportant, yet still small enough to avert substrate interactions. High strain hardening, particularly that for pure metals attached to substrates, could be a factor. Crystallographic texturing that develops upon either bonding or deposition $[35,36,82,83]$ may also be important. These differences remain to be resolved. For the present purposes, the trilayer test results are used (Table 2) since they represent the in-plane deformation characteristics of the metal layer at small plastic strains.

The plasticity length scales have only been measured on two of the pure metals used in the adhesion tests, namely $\mathrm{Cu}$ [76] and $\mathrm{Ni}$ [20]. The results are summarized in Table 2. It has been surmised that these length scales are similar for all annealed, pure metals, but would decrease in the presence of hardening mechanisms [72]. For the following analyses, it is assumed that $\ell_{\mathrm{R}}(\approx 5 \mu \mathrm{m})$ and $\ell_{\mathrm{S}}$ $(\approx 0.5 \mu \mathrm{m})$.

\subsection{Work of adhesion}

Comparison between measurements and theory requires that both $W_{\text {ad }}$ and $\hat{\sigma}$ be known, including the effects of segregation. Sparse information exists from the combination of experiment and first principles calculations (Fig. 13). Work-of-adhesion measurements have been made for $\mathrm{Al}_{2} \mathrm{O}_{3}$ with a range of pure metals [84] (Table 2). However, there have only been two measurements of the effect of segregation [19, 47, 48] (Table 2). Calculations have provided useful insights, especially about the varied roles of segregants on both $W_{\text {ad }}$ and $\hat{\sigma}$ [59-61]. But, systematic trends have yet to be established.

\section{INTERFACE RUPTURE MODELS}

\subsection{Generalities}

Each of the three models predicts different trends with the adhesion parameters (Fig. 2). Getting the mechanism right is crucial. Such assessment has been made by direct experimental observations of the crack tip upon crack growth, elaborated in Section 3.

In one model, the interface cracks are presumed to be atomically sharp ( $\mathrm{I}$ in Figs 1 and 2). In order to introduce plasticity, a length scale must be chosen. One approach imagines an elastic zone, width $D$, near the crack (Fig. 1). This zone allows the sharp tip assertion to be retained [6, 8]. Accordingly, because the stress is singular, crack growth may be considered to occur when the energy release rate at the crack tip, $G_{\text {tip }}$, attains the workof-adhesion.
In many cases, the interface crack blunts before propagation, even when $\Gamma_{i}$ is relatively low (10-20 J/ $\mathrm{m}^{2}$ ). When this happens, the stress can no longer be modeled as singular. Accordingly, it is necessary to simultaneously satisfy stress and adhesive energy criteria. There are two sub-criteria. One involves crack injection and the other a fracture process zone.

(i) One blunt crack model comprises a crack tip rupture zone (II in Figs 1 and 2) consisting of voids and debonds that initiate, grow and coalesce, similar in concept to a ductile fracture process zone in metals. There is a resistance curve characterized by a steady-steady toughness, $\Gamma_{\mathrm{ss}}$, relative to the process zone toughness, $\Gamma_{0}[4$, 12]. Here, $\Gamma_{0}$ is not the work-of-adhesion. Instead $\Gamma_{0}$ and $\hat{\sigma}$ characterize a fracture process comprising void growth.

(ii) The other blunt crack model pertains to stationary cracks (III in Figs 1 and 2). It characterizes the initiation toughness, in a manner analogous to steels below the ductile-to-brittle transition temperature [13]. That is, the stress field ahead of the blunt crack interacts with weak patches along the interface. When the most severe of these patches debond, a crack forms and extends unstably, causing brittle failure.

Mechanisms I and II have emphasized steady-state crack advance. Both involve a fracture zone along the crack plane. It should be possible to identify a unified model that provides a natural transition between the two mechanisms. An attempt is presented below.

\subsection{Models emphasizing steady-state toughness}

8.2.1. Atomically-sharp cracks: the SSV model. The SSV model of Suo et al. [8] assumes that dislocations are not emitted at the crack tip and imposes an elastic zone of height $D$ above the interface in the metal. Plastic deformation characterized by $\sigma_{0}$ and $N$ occurs outside the elastic zone. Because the tip is surrounded by an elastic region the stresses at the tip are singular. Accordingly, the only barrier to bond rupture is the requirement that the energy release rate attains the work-of-adhesion. This criterion fully prescribes the model, with the understanding that $D$ is a fitting parameter. (An effort to determine $D$ using dislocation mechanics has been attempted [6], but will not be invoked here.)

For a mode I loading of the interface under small scale yielding, the steady-state limiting toughness varies in the manner summarized on Fig. 2(a). The primary dependencies of $\Gamma_{\mathrm{ss}} / \Gamma_{0}$ are on $D / R_{0}$ and $N$, where $R_{0}$ is defined in equation (3). Strain gradient plasticity effects become important if $D$ is smaller than or comparable to $\ell$. Eventually, it will be required that these two length scales be replaced by a single scale based on dislocation dynamics. 
8.2.2. Crack tips surrounded by plasticity: the $E P Z$ model. If plasticity is imagined to extend to the crack tip, the criterion invoked in the SSV model cannot be employed because the energy release rate at the tip is always zero. This is why $\Gamma_{\mathrm{ss}} / \Gamma_{0}$ predicted by the SSV model becomes unbounded as $D$ approaches zero. The embedded process zone (EPZ) model [4, 5] adopts a tractionseparation relation as the description of the interface [Fig. 1(II)]. The relation is prescribed using a potential with $\Gamma_{0}$ as the work of separation and $\hat{\sigma}$ as the peak separation stress under a strict mode I opening. The metal above the interface is described by continuum plasticity with parameters $\sigma_{0}$ and $N$, supplemented by the material length scale $\ell$ if the strain gradient theory is used. The model is fully specified such that the dependencies of the crack growth resistance $\Gamma_{\mathrm{R}}(\Delta a)$ can be computed in terms of the interface parameters, $\Gamma_{0}$ and $\hat{\sigma}$ and the continuum properties of the metal and oxide. In particular, the steady-state toughness depends on the main parameters according to:

$$
\frac{\Gamma_{\mathrm{ss}}}{\Gamma_{0}}=F\left(\frac{\hat{\sigma}}{\sigma_{0}}, N, \frac{\ell}{R_{0}}\right) .
$$

Plots of this relation are shown on Fig. 2, for a
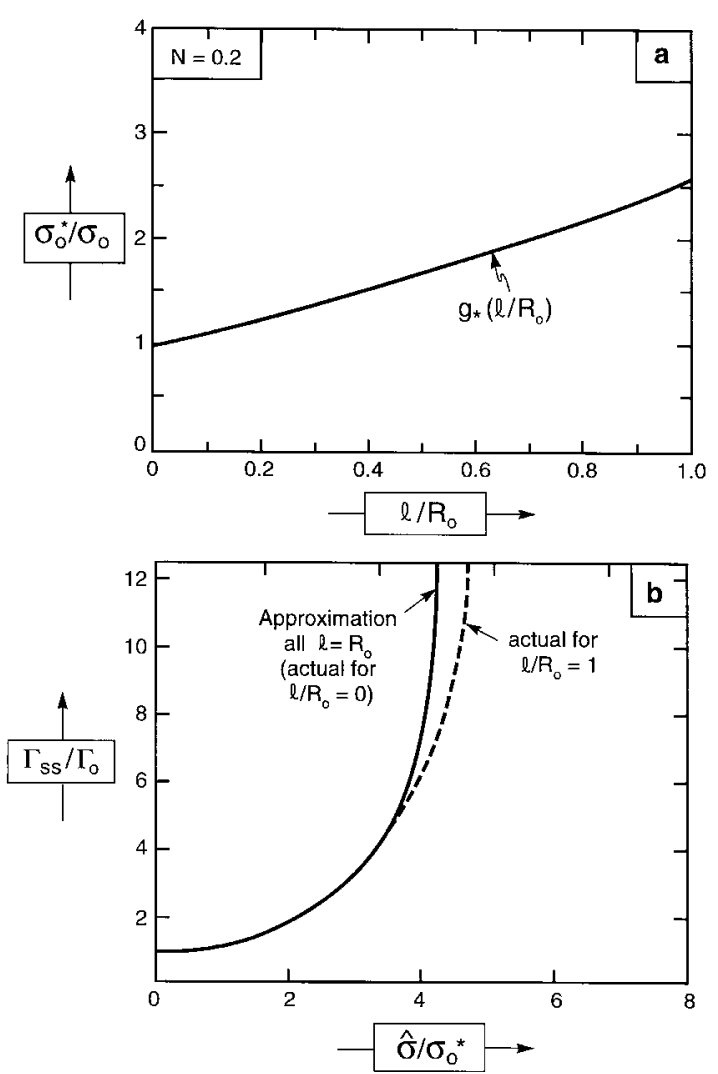

Fig. 16. (a) Rescaling factors for the yield strength in the embedded process zone model. (b) The effect of the plasticity length scale on the steady-state interface toughness for a process zone mechanism.
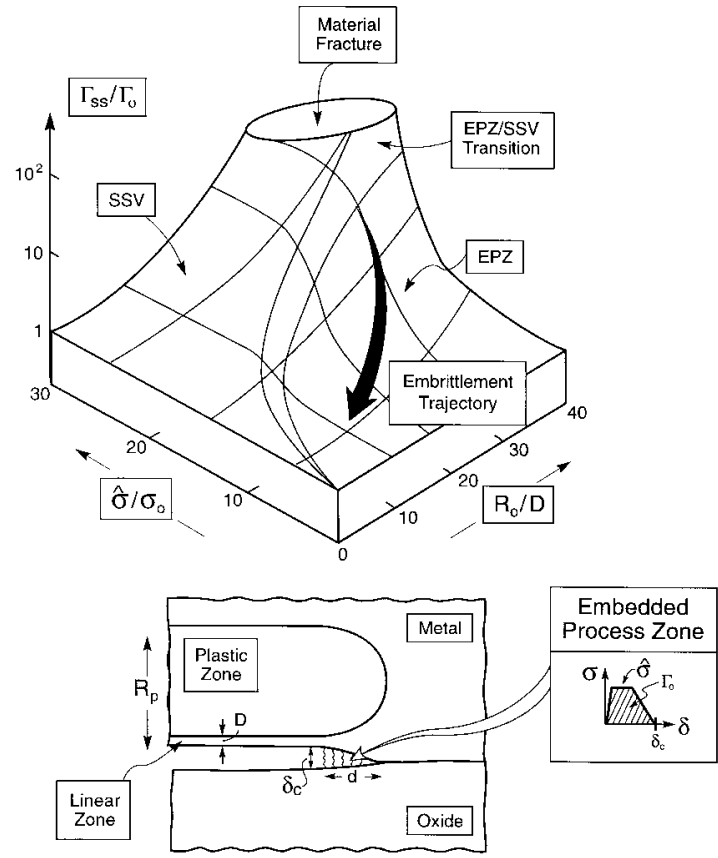

Fig. 17. The fracture surface predicted by the unified zone model including the truncation when material failure intervenes and the embrittlement trajectory caused by segregants.

metal characterized by conventional plasticity $(\ell=0)$.

An approximate way to account for the dependence of the toughness on $\ell / R_{0}$ is to use the conventional plasticity predictions with a scale-adjusted yield strength $\sigma_{0}^{*}$. The approximation then uses the conventional plasticity result with $\sigma_{0}^{*}$ replacing $\sigma_{0}$ :

$$
\frac{\Gamma_{\mathrm{ss}}}{\Gamma_{0}}=F\left(\frac{\hat{\sigma}}{\sigma_{0}^{*}}, N, 0\right)
$$

where

$$
\sigma_{0}^{*} / \sigma_{0}=g\left(\ell / R_{0}, N\right)
$$

is plotted on Fig. 16(a). The plot has been obtained by fitting results determined by Wei and Hutchinson [22]. The corresponding trend in steady-state toughness for $N=0.2$ is plotted on Fig. 16(b), showing that the approximation is highly effective.

The EPZ model predicts essentially unbounded toughness if the interface strength exceeds a critical value (e.g. $\hat{\sigma} / \sigma_{0}^{*} \cong 5$ for $N=0.2$ ). This suggests a ductile-to-brittle transition (DBT) analogous to that found in steels. Here, however, it would be a transition from interface fracture to failure of one of the constituent materials. In terms of actual stresses, this transition becomes much less abrupt as the relative length scale, $\ell / R_{0}$, increases.

8.2.3. The unified zone model. The unified model coincides with the SSV and EPZ models at their respective limits and provides the transition between 
(a)
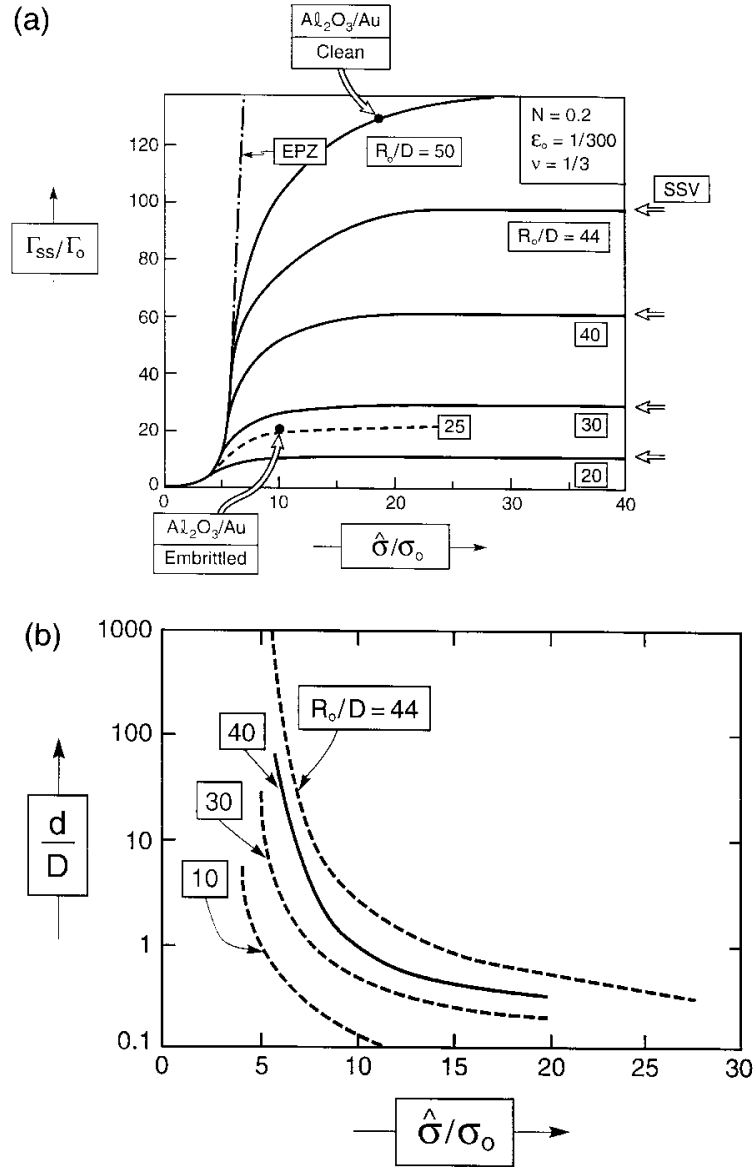

Fig. 18. Predictions of the unified zone model [77] (a) effects of strength and scale indices on steadystate toughness; (b) the relative sizes of the process zone, $d$, and the dislocation free zone, $D$.

them. The model (Fig. 17) employs both the elastic zone of thickness $D$ in the metal above the interface and the traction-separation relation at the interface. Accordingly, the model employs all the parameters from the other two models. That is, $\Gamma_{0}, \hat{\sigma}$ and $D$ specify the interface and the elastic zone, whereas $\sigma_{0}, N$ and $\ell$ specify the metal plasticity.

The length of the process zone over which interface separation occurs is denoted by $d$. It is a computed quantity. If $d \ll D$, the process zone lies deep within the elastic zone, such that attainment of $\hat{\sigma}$ ceases to be controlling and the SSV limit pertains. At the other limit, $d \gg D$, the elastic zone has essentially no influence and the EPZ model holds. These two limits and the transition between them are seen on Fig. 18, where curves of $\Gamma_{\mathrm{ss}} / \Gamma_{0}$ are plotted as a function of $\hat{\sigma} / \sigma_{0}$ for fixed values of $D / R_{0}$ using conventional plasticity $(\ell=0)$, with $N=0.2$. The results have been computed for the mode I problem in a homogeneous metal, but the trends are expected to closely replicate those for the bimaterial interface under nominally mode I conditions.

The dominant features are revealed in schematic form in Fig. 17, visualized as a "fracture toughness surface" with distinct demarcations of the domains wherein the EPZ and SSV models predominate. Interfaces with high $R_{0} / D$ and low $\hat{\sigma} / \sigma_{0}$ are described by the EPZ limit, while the SSV limit applies to interfaces with low $R_{0} / D$ and high $\hat{\sigma} / \sigma_{0}$. The transition between the two comprises a large portion of parameter space, as will be evident from attempts to apply the model to interpret experimental data in Section 9. The plasticity length scale would modify these predictions when $\ell$ is comparable to $R_{0}$. The trend would be captured by Fig. 17 if $\sigma_{0}$ were replaced by $\sigma_{0}^{*}$ from equation (9), both in the strength index, $\hat{\sigma} / \sigma_{0}$, and in the definition of $R_{0}$ [equation (3)]. This approximation is much less accurate in the SSV limit than in the EPZ limit and should be regarded as qualitative.

\subsection{Stationary cracks: initiation toughness}

Upon blunting of a stationary crack, fracture can proceed when the peak stress is large enough to inject a dynamic debond that extends abruptly along the interface (mechanism III in Fig. 1). This criterion is the same as that used to successfully predict cleavage fracture in steels, as well as their ductile-to-brittle transition [13, 14]. It implicitly requires that there be a large enough energy release 
to drive the crack once injected. In turn, this requires high strain-rate sensitivity. The toughness determined is that at initiation. There is no resistance curve. The process is inherently stochastic and requires information about weak links at the interface, regarded as weak patches caused by precipitation, heterogeneous segregation, etc.

The strength index for this model is, $\hat{\sigma}=\sqrt{\bar{E} \Gamma_{0} / R_{\mathrm{u}}}$, with $R_{\mathrm{u}}$ the radius of the largest weak patch. The toughness trend (without the length scale) is illustrated in Fig. 2(c). Note that there is a transition to ductility when $\hat{\sigma}$ exceeds a critical level, dependent on the strain hardening (Appendix). It occurs when the yield strength satisfies equation (A5):

$$
\hat{\sigma} / \sigma_{0}=2 \beta / \sqrt{\pi}
$$

where $\beta$ is in the range $3-5$ as $N$ varies from 0.2 to 0.1 .

At $\hat{\sigma}$ levels above the transition, another failure mechanism is needed to cause crack growth. In steels, this mechanism comprises hole growth and coalescence. At interfaces, a process zone mechanism is presumed.

The plasticity length scale ameliorates the abruptness of the transition and also affects the toughness at smaller $\hat{\sigma}$. Revised toughnesses can be estimated by accounting for the elevated stresses ahead of the tip associated with $\ell$, as discussed in Section 6.

\section{COMPARISON WITH MODELS}

It is not a trivial matter to compare the adhesion measurements with the preceding models because so many parameters are involved. To make progress, as much experimental information as possible is used (Tables 1 and 2). Analysis begins with the observations of extensive blunting at stationary cracks on interfaces between sapphire with $\mathrm{Al}, \mathrm{Cu}$ and $\gamma$ $\mathrm{Ni}(\mathrm{Cr})$, as well as "clean" $\mathrm{Au}$ and Ni (and by inference, $\mathrm{Pt}$ ) and "clean" $\mathrm{Nb}$. These observations contrast with the minimal blunting found (between sapphire and $\mathrm{Au}$ or $\mathrm{Ni}$ ) either when loads are imposed in a moist atmosphere or when contaminants are infused into the interface. They also contrast with the consistently brittle behavior found with Mo. The measurements reveal a corresponding reduction in toughness by one or two orders of magnitude between "clean" and segregated interfaces. The challenge is to establish a modeling basis that accounts for these dramatic changes.

The difference cannot be attributed to the yield strength, because this is unchanged upon infusing segregants and, moreover, a vast range in $\sigma_{0}$ is encompassed by the measurements (Table 2). It must be related to the bonding parameters, $W_{\text {ad }}$ and $\hat{\sigma}$. Making distinctions based solely on $W_{\text {ad }}$ does not suffice. This quantity changes by less than a factor 2 (from about $0.8 \pm 0.1$ to $0.4 \pm 0.1 \mathrm{~J} / \mathrm{m}^{2}$ ) during the segregant infusion process. According to Fig. 18(a), such reductions would at most diminish $\Gamma_{\mathrm{ss}}$ by a factor of 5 , whereas the measurements indicate changes in excess of a factor of 100 . Consequently, the bond strength, $\hat{\sigma}$, must have a major role. Experimental determination of this quantity can only be made by means of a laser spalling technique [24] that is difficult to implement. It can be calculated using first principles methods (Fig. 13), but the method is intensive and there is debate about the veracity of the results.

Thus, it is not possible to unambiguously and explicitly compare the measurements with the available models, even when $W_{\text {ad }}$ (as well as $\Gamma_{\text {ss }}$ and $\sigma_{0}$ ), are known, absent information about $\hat{\sigma}$, since $D$ is a fitting parameter. The best that can be accomplished is a rationalization. The measurements made on $\mathrm{Al}_{2} \mathrm{O}_{3} / \mathrm{Au}$ are used for this purpose, based on the indices presented on Table 2. While changes in $\hat{\sigma}$ are unknown, the form of the first principles calculations suggests that reduction in $\hat{\sigma}$ upon segregation should not exceed the reduction in $W_{\text {ad }}$ (Fig. 13), because both are about equally affected by the increase in the equilibrium atom spacing across the interface. It is thereby assumed that changes in $\hat{\sigma}$ and $W_{\text {ad }}$ are proportional.

The analysis is performed as follows. (i) Find values for $\hat{\sigma}$ and $D$ that allow small $\Gamma_{\mathrm{ss}}$ in the embrittled state at the measured $W_{\text {ad }}$. (ii) Increase $\hat{\sigma}$ such that large changes in $\Gamma_{\mathrm{ss}}$ occur with relatively small (and comparable) increases in both $W_{\text {ad }}$ and $\hat{\sigma}$. The result is shown on Fig. 18(a). Since the $W_{\text {ad }}$ is specified, as well as $\sigma_{0}$, this procedure provides remarkably limited scope in the choices of $D$ and $\hat{\sigma}$ needed to achieve the requisite variation in $\Gamma_{\mathrm{ss}}$. It requires that $D \approx 200 \mathrm{~nm}$ and, absent segregation, $\hat{\sigma}$ $\approx 1 \mathrm{GPa}$, with $W_{\text {ad }}=0.6 \mathrm{~J} / \mathrm{m}^{2}$. Upon $\mathrm{C}$ infusion, $\hat{\sigma}$ decreases to $\sim 500 \mathrm{MPa}$ as $W_{\text {ad }}$ reduces to $0.3 \mathrm{~J} / \mathrm{m}^{2}$. The zone model then predicts a toughness that changes from 70 to $5 \mathrm{~J} / \mathrm{m}^{2}$. This compares with a measured change from 200 to $2 \mathrm{~J} / \mathrm{m}^{2}$.

The inferred $\hat{\sigma}$ for the clean interface is much lower than that calculated for other metal/oxide interfaces (Fig. 13). The reasons are not understood, but need to be resolved to make further progress. Accounting for the plasticity length scale $\ell$ would lead to larger values of $\hat{\sigma}$ by a factor of 3 or more. Moreover, the predicted changes in toughness are still less than the measurements. The inability to fully capture the experiments reflects the incomplete nature of the unified model, which has yet to embrace all aspects of the transition from sharp to blunt cracks. Introducing the plasticity length scale in accordance with the schemes described above does not achieve the desired effects. The future modeling challenge is to appropriately incorporate this transition. 


\section{CONCLUSION}

Progress has been made toward a robust methodology for measuring the adhesion energy for bimaterial interfaces. New approaches for simulating interface rupture have also been forthcoming, inclusive of a framework that enables length scale linkages between atomistics and continuum. While progress is not yet sufficient to enable explicit comparison between measurement and theory, the modeling schemes provide useful insights about factors that lead to embrittlement. Significant modeling challenges remain. In particular, a satisfactory approach for including the transition from sharp to blunt interface cracks is lacking. Additionally, combined experimental and theoretical approaches for determining the bond rupture strength, $\hat{\sigma}$, have yet to be formalized. This is an important deficiency, since it has now been established that $\hat{\sigma}$ has a key role in interface rupture, additional to that associated with the work of adhesion.

Careful experimental measurements have revealed that most metal/oxide interfaces are inherently tough and strong, consistent with first principles calculations. That is, in clean systems (absent segregrants and reaction products), pre-cracks introduced at the interface plastically blunt and eliminate high stress concentrations. When failure occurs, it happens in one of the adjoining materials, not at the interface, either by brittle fracture of the oxide or ductile fracture of the metal. The one possible exception is $\mathrm{Al}_{2} \mathrm{O}_{3} / \mathrm{Mo}$, which appears to be always brittle.

The introduction of certain segregants results in brittle, weak interfaces having low adhesion energies $\left(1-20 \mathrm{~J} / \mathrm{m}^{2}\right)$. The measurements have established that $\mathrm{C}$ embrittles $\mathrm{Al}_{2} \mathrm{O}_{3} / \mathrm{Au}, \mathrm{S}$ embrittles $\mathrm{Al}_{2} \mathrm{O}_{3} / \mathrm{Ni}$ and $\mathrm{Ag}$ weakens $\mathrm{Al}_{2} \mathrm{O}_{3} / \mathrm{Nb}$. First principles calculations reveal that interstitial $\mathrm{S}$ embrittles $\mathrm{MgO} / \mathrm{Al}$. However, the picture is incomplete, because toughness measurements and first principles calculations have yet to be performed on the same interfaces. Moreover, the specificity of segregant embrittlement has still to be adequately understood.

Various other findings must also be consistent with the overall picture. Interfacial precipitates of $\mathrm{FeAl}_{3}$ embrittle $\mathrm{Al}_{2} \mathrm{O}_{3} / \mathrm{Al}$, while $\mathrm{CuO}_{2}$ embrittles $\mathrm{Al}_{2} \mathrm{O}_{3} / \mathrm{Cu}$. Moisture embrittles both $\mathrm{Al}_{2} \mathrm{O}_{3} / \mathrm{Au}$ and $\mathrm{Al}_{2} \mathrm{O}_{3} / \mathrm{Ni}$ by stress corrosion. Finally, $\mathrm{Cr}$ and Ti "adhesion layers" suppress embrittlement, seemingly because they getter the segregants and contaminants that cause the problem.

\section{REFERENCES}

1. Rice, J. R., J. appl. Mech., 1988, 55, 98.

2. Hutchinson, J. W. and Suo, Z., Adv. appl. Mech., 1992, 29, 63.

3. Rice, J. R., Drugan, W. J. and Sham, T.-L., in Elastic-Plastic Analysis of Growing Cracks, ASTM
STP 7008. American Society for Testing and Materials, Philadelphia, PA, 1980, pp. 189-221.

4. Tvergaard, V. and Hutchinson, J. W., J. Mech. Phys. Solids, 1993, 41, 1119

5. Wei, Y. and Hutchinson, J. W., J. Mech. Phys. Solids, 1997, 45, 1137.

6. Beltz, G., Rice, J. R., Shih, C. F. and Xia, L., Acta mater., 1996, 44, 3943.

7. O'Dowd, N. P. and Shih, C. F., J. Mech. Phys. Solids, 1991, 39, 989

8. Suo, Z., Shih, F. and Varias, A., Acta metall. mater., 1993, 41, 1551.

9. Bagchi, A. and Evans, A. G., Interface Sci., 1996, 3, 169.

10. Zywicz, E. and Parks, D. M., J. Mech. Phys. Solids, $1992,40,511$.

11. Anderson, T. J., Fracture Mechanics, Fundamentals and Applications. CRC Press, Boca Raton, FL, 1989.

12. Tvergaard, V. and Hutchinson, J. W., J. Mech. Phys. Solids, 1992, 40, 1377.

13. Ritchie, R. O., Knott, J. and Rice, J. R., J. Mech Phys. Solids, 1973, 21, 395.

14. Lin, T., Evans, A. G. and Ritchie, R. O., J. Mech Phys. Solids, 1986, 34, 477.

15. McMeeking, R. M. and Parks, D. M., in On Criteria for J-Dominance of Crack Tip Fields in Large-Scale Yielding, ASTM STP 668. American Society for Testing and Materials, Philadelphia, PA, 1979, pp 175-194.

16. Kanninen, M. F. and Popelar, C. H., Advanced Fracture Mechanics. Oxford University Press, Oxford, 1985.

17. Evans, A. G., J. Am. Ceram. Soc., 1990, 73, 187.

18. Oh, T. S., Cannon, R. M. and Ritchie, R. O., J. Am. Ceram. Soc., 1987, 70, 253.

19. Lipkin, D. M., Clarke, D. R. and Evans, A. G., Acta mater., 1998, 46, 4835.

20. Stölken, J. S. and Evans, A. G., Acta mater., 1998, 46, 5109.

21. Fleck, N. A. and Hutchinson, J. W., in Advances in Applied Mechanics, Vol. 33, ed. J. W. Hutchinson and T. Y. Wu, 1997, pp. 295-361

22. Wei, Y. and Hutchinson, J. W., J. Mech. Phys. Solids, 1997, 45, 1253.

23. Fleck, N. A. and Hutchinson, J. W., J. Mech. Phys. Solids, 1993, 41, 1825.

24. Gupta, V., Argon, A. S., Parks, D. M. and Cornie, J. A., J. Mech. Phys. Solids, 1992, 40, 141.

25. Evans, A. G. and Dalgliesh, B. J., Acta metall. mater., 1992, 40, S295.

26. He, M. Y. and Evans, A. G., Acta metall. mater. 1991, 38, 1587.

27. Moody, N. R., Hwang, R. Q., Venkataraman, S., Angelo, J. E., Norwood, D. P. and Gerberich, W. W., Acta mater., 1998, 46, 585.

28. Leung, D. K., He, M. Y. and Evans, A. G., J. Mater. Res., 1995, 10, 1693.

29. Bagchi, A., Lucas, G. E., Suo, Z. and Evans, A. G., $J$. Mater. Res., 1994, 9, 1734.

30. He, M. Y., Turner, M. R. and Evans, A. G., Acta metall. mater., 1995, 43, 3453.

31. Turner, M. R., Dalgleish, B. J., He, M. Y. and Evans, A. G., Acta metall. mater., 1995, 43, 3459.

32. Charalambides, P. G., Lund, J., Evans, A. G. and McMeeking, R. M., J. appl. Mech., 1989, 111, 77.

33. Jensen, H. M. and Thouless, M. D., Int. J. Solids Struct., 1993, 30, 779.

34. Ritter, J. E., Fox, J. R., Hutko, D. J. and Lardner, T. J., J. Mat. Sci., 1999, 33, 4581 .

35. Reimanis, I., Dalgleish, B. J. and Evans, A. G., Acta metall. mater., 1991, 39, 3133

36. Turner, M. and Evans, A. G., Acta metall. mater., 1996, 44, 863 
37. Kinloch, A. J., Lau, C. C. and Williams, J. G., Int. J. Fract., 1994, 66, 45.

38. Kim, K.-S. and Aravas, N., Int. J. Solids Struct., 1988, 24, 417.

39. Wei, Y. and Hutchinson, J. W., Interface strength, work of adhesion and plasticity in the peel test. Report Mech 315, Division of Engineering and Applied Sciences, Harvard University, 1997.

40. Drory, M. D. and Hutchinson, J. W., Proc. R. Soc., 1996, 452, 2319.

41. Vlassak, J. J., Drory, M. D. and Nix, W. D., J. Mater. Res., 1997, 12, 1900.

42. Wang, J. S., Sugimura, Y. and Evans, A. G., Thin Solid Films, 1998, 325, 163.

43. Begley, M. R., Evans, A. G. and Hutchinson, J. W., Int. J. Solids Structures, 1999, 36, 2773.

44. Zhuk, A. V., Evans, A. G., Hutchinson, J. W. and Whitesides, G. M., J. Mater. Res., 1998, 13, 3555.

45. He, M. Y., Evans, A. G. and Hutchinson, J. W., Acta mater., 1997, 45, 3481.

46. Dalgleish, B. J., Saiz, E., Tomsia, A. P., Cannon, R. M. and Ritchie, R. O., Scripta metall. mater., 1994 31, 1109.

47. Korn, D., Elsnner, G., Fischmeister, H. F. and Rühle, M., Acta metall. mater., 1992, 40, S335.

48. Elsnner, G., Korn, D. and Rühle, M., Scripta metall. mater., 1994, 31, 1037.

49. Reimanis, I. E., Trumble, K. P., Rogers, K. A. and Dalgleish, B. J., J. Am. Ceram. Soc., 1997, 80, 424.

50. Gaudette, F. A., Suresh, S., Evans, A. G., Dehm, G. and Rühle, M., Acta mater., 1997, 45, 3503.

51. McNaney, J. M., Cannon, R. M. and Ritchie, R. O., Acta mater., 1996, 44, 4713.

52. Dalgleish, B. J., Trumble, K. P. and Evans, A. G., Acta metall. mater., 1989, 37, 1923.

53. Bartlett, A. and Evans, A. G., Acta metall. mater. 1993, 41, 497.

54. Bonnell, D. and Kiely, J., Physica status solidi, 1998, 166, 7

55. Ma, Q., Fujimoto, H., Flinn, P., Jain, V., Adibi-Rizi, F. and Dauskardt, R. H., Materials Reliability in Microelectronics V, Proc. MRS Annual Meeting, San Francisco, CA, 1995, p. 91.

56. Ma, W., Bumgartner, J., Fujimoto, H., Land, M. and Dauskardt, R. H., Materials Reliability in Microelectronics VII, Proc. MRS Annual Meeting, San Francisco, CA, 1997, pp. 3-14.

57. Lane, M., Dauskardt, R. H., Ware, R., Ma, Q. and Fujimoto, H., Materials Reliability in Microelectronics VII, Proc. MRS Annual Meeting, San Francisco, CA, 1997, pp. 3-14.

58. De Graef, M., Dalgleish, B. J., Turner, M. R. and Evans, A. G., Acta metall. mater., 1992, 40, S333.

59. Raynolds, J. E., Smith, J. E., Zhao, G. L. and Srolovitz, D. J., Phys. Rev. B, 1996, 53, 13883.

60. Hong, T., Smith, J. R., Srolovitz, D. J., Gay, J. G. and Richter, R., Phys. Rev. B, 1992, 45, 8775.

61. Hong, T., Smith, J. R. and Srolovitz, D. J., Phys. Rev. $B, 1993, \mathbf{4 7}, 13615$

62. Finnis, M. W., J. Phys.: Condens. Matter, 1996, 8, 5811.

63. Begley, M. and Hutchinson, J. W., J. Mech. Phys. Solids, 1998, 46, 2049.

64. Ma, Q. and Clarke, D. R., J. Mater. Res., 1995, 10, 853.

65. Pethica, J. B., Hutchings, R. and Oliver, W. C., Phil. Mag. A, 1983, 48, 593.

66. Poole, W. J., Ashby, M. F. and Fleck, N. A., Scripta metall. mater., 1996, 34, 559.

67. Stelmashenko, N. A., Walls, M. G., Brown, L. M and Miman, Y. V., Acta metall. mater., 1993, 41, 2855.
68. Hutchinson, J. W., Micro-Mechanics of Damage in Deformation and Fracture, Solid Mechanics. Technical University of Denmark, 1989.

69. Cox, B. N. and Marshall, D. B., Acta metall. mater., 1994, 42, 341

70. Rice, J. R., Drugan, W. J. and Sham, T. L., in Fracture Mechanics: Twelfth Conference, ASTM STP 700. American Society for Testing and Materials, Philadelphia, PA, 1980, pp. 189-221.

71. Budiansky, B., Amazigo, J. C. and Evans, A. G., $J$. Mech. Phys. Solids, 1988, 36, 167.

72. Moran, B., Ortiz, M. and Shih, C. F., Int. J. Numer. Meth. Engng, 1990, 29, 483.

73. Kamat, S. V., Hirth, J. P. and Mehrabian, R., Scripta metall., 1989, 23, 523.

74. Smyshlaev, V. P. and Fleck, N. A., J. Mech. Phys Solids, 1996, 44, 465.

75. Nix, W. D. and Gao, H., J. Mech. Phys. Solids, 1998 , 46, 11

76. Fleck, N. A., Muller, G. M., Ashby, M. F. and Hutchinson, J. W., Acta metall. mater., 1994, 42, 475.

77. Wei, Y. and Hutchinson, J. W., Int. J. Fracture, 1999 , 95, 1.

78. Smialek, J. L., Jayne, D. T., Schaeffer, J. C. and Murphy, W. H., Thin Solid Films, 1994, 253, 285.

79. Smeggil, J. G., Funkenbusch, A. W. and Borstein, N. S., Metall. Trans. A, 1986, 17, 923.

80. McVay, R. V., Williams, P., Meier, G. H., Pettit, F. S. and Smialek, J. L., in Superalloys 92, ed. S. D. Antolovich. The Metallurgical Society of AIME, Warrendale, PA, 1992, p. 807

81. O'Dowd, N. P., Stout, M. G. and Shih, C. G., Phil. Mag. A, 1992, 66, 1037.

82. Suresh, S., Giannakopoulos, A. G. and Olsson, M., $J$. Mech. Phys. Solids, 1994, 42, 979.

83. Zielinski, E. M., Vinci, R. P. and Bravman, J. C., $J$. appl. Phys., 1994, 76, 4516.

84. Pilliar, R. M. and Nutting, J., Phil. Mag., 1967, 16, 181.

85. Wang, J. S. and Evans, A. G., Acta mater., 1998, 46, 4993.

\section{APPENDIX}

\section{Cleavage by Crack Injection}

Crack injection concepts have been fully developed for analysis of cleavage fracture in steels as well as the associated ductile-to-brittle transition [13, 14]. Briefly, deformation incompatibility between carbide particles and the ferrite cause the particles to crack. The cracks that develop become dynamic. They inject into the ferrite because they attain a velocity wherein the dynamic toughness $\Gamma_{0}$ of the ferrite becomes anomalously low. Injection occurs if the energy release rate exceeds $\Gamma_{\mathrm{D}}$ when the crack reaches the carbide/ferrite interface. This criterion requires that the stress on the particle within the elastic/plastic field exceed a critical value, $S$, given by

$$
S=\sqrt{\pi E \Gamma_{\mathrm{D}} / 4 R}
$$

where $R$ is the particle radius. The interface analogy to carbide particles would be weak patches [mechanism III on Fig. 1(c)], caused by precipitation, segregants, etc. Accordingly, $R$ is subject to a size and spatial distribution.

The median interface toughness, $\Gamma_{\mathrm{c}}$, in the absence of strain gradient effects is [14]:

$$
\frac{E \Gamma_{\mathrm{c}}}{S_{\mathrm{u}}^{2}}\left(\eta^{3 / 2} b\right)^{1 / 2}=\left[A^{1 / 2}(m, N)\right]\left(\frac{S_{*}}{S_{\mathrm{u}}}\right)^{m / 2}\left(\frac{S_{\mathrm{u}}}{\sigma_{0}}\right)^{1 / N-1} .
$$

The non-dimensional coefficient $A$, determined by numerical integration, is of order unity. $\eta$ is the number of 
patches per unit area and $b$ is the crack perimeter. The quantity $S_{\mathrm{u}}$ is a minimum injection stress, with $S_{*}$ a weakest link scale parameter and $m$ a shape parameter. Replacing terms in $S$ with $R$ using equation (A1) gives:

$$
\begin{aligned}
\frac{\Gamma_{\mathrm{c}}}{\Gamma_{0}}= & \left(\frac{A}{\eta^{3 / 2} b}\right)^{1 / 2}\left(\frac{\pi}{4}\right)^{(1 / N+1) / 2}\left(\frac{R_{\mathrm{u}}}{R_{*}}\right)^{m / 4}\left[\frac{E \Gamma_{\mathrm{D}} / R_{\mathrm{u}}}{\sigma_{0}^{2}}\right]^{(1 / N-1) / 2} \\
& \equiv \chi\left(\hat{\sigma} / \sigma_{0}\right)^{1 / N-1}
\end{aligned}
$$

where $\hat{\sigma}=\sqrt{E \Gamma_{\mathrm{D}} / R_{\mathrm{u}}}$.

At this level of analysis, $\chi$ is simply a fitting parameter. By equating $S_{\mathrm{u}}$ to the peak tensile stress ahead of the crack

$$
\sigma_{\max }=\beta(N) \sigma_{0}
$$

where $\beta$ is between 3 and 5 for continuum plasticity, a brittle-to-ductile transition is predicted [Fig. 2(c)]. It occurs when

$$
\sigma_{0}=\sqrt{\frac{\pi E \Gamma_{\mathrm{D}}}{4 \beta^{2} R_{\mathrm{u}}}} .
$$

The effect of the plasticity length scale [equation (6)] has yet to be rigorously included in the model. It can be approximated by using a volume average of the stress elevation caused by $\ell$ within the domain nearest the crack $\left(r / R_{0} \approx 0.1\right.$, Fig. 12). When this is done, the effect is comparable to an increase in the yield strength, characterized by

$$
\sigma_{0}^{*} \approx \sigma_{0}\left[1+2 \ell / R_{0}\right]
$$

